\title{
Análise do impacto do progresso tecnológico nos custos do tratamento hospitalar: o caso do tratamento para litíase urinária no Hospital Universitário de Brasília
}

\author{
Analysis of the technological change impact in the costs in hospital treatment: \\ the case study of the treatment for urinary calculi in Hospital in University \\ Hospital of Brasilia.
}

Patrícia de Souza Costa

César Augusto Tibúrcio Silva "

\begin{abstract}
Resumo
O progresso tecnológico na área de saúde tem provocado a elevação dos custos da assistência médica, preocupando a população mundial, os agentes privados e os responsáveis pelas politicas públicas. Este trabalho apresenta uma análise do impacto do progresso tecnológico - delimitado, neste estudo, à incorporação de equipamentos médicos - nos custos do tratamento hospitalar. Para cumprir o objetivo, foram escolhidos os tratamentos médicos para litíase urinária litotripsia e cirurgia - devido ao histórico de relevantes avanços tecnológicos. 0 estudo de caso foi realizado no Serviço de Litotripsia e no Centro Cirúrgico do Hospital Universitário de Brasilia (HUB), no período de 2001 a 2003. Foram comparados os custos e as receitas diferenciais das alternativas de tratamento para calculose urinária em quatro opções de decisão. Para testar a robustez dos resultados, foi incorporada a variável incerteza, por meio de simulações no sistema Crystall Ball, realizando 50.000 iterações. Os principais impactos do progresso tecnológico nos custos do tratamento para litíase urinária são: aumento da capacidade instalada, geração de despesa com obsolescência e aumento das receitas.
\end{abstract}

Palavras-chave: Custos hospitalares. Progresso tecnológico. Capacidade. Depreciação

\begin{abstract}
The technological progress in the field of health has been triggering rises of medical assistance costs, worrying the worldwide population, private agents and the responsible ones for public policies. This search presents an analysis of technological evolution impact - here, bounded to the medical equipments incorporation - on the hospital treatment costs. In order to accomplish the objective, the medical care for urinary lithiasis - lithotripsy and surgery - had been chosen due to the record of meaningful technological advances. The case study was carried through at the Lithotripsy Service and Hospital Universitário de Brasilia (HUB) Surgical Center from 2001 to 2003. The costs and incomes differential items inherent to options for urinary calculosis treatment - were compared in four proposals. As a means to prove the results robustness, the variable uncertainty was incorporated through simulations at the Crystal Ball system, achieving 50.000 iterations. The main impacts from technological progress on the medical care for urinary lithiasis costs are: increase of the installed capacity, generation of expense with obsolescence and increase of revenues.
\end{abstract}

Key words: Hospital Costs. Technological Progress. Capacity. Depreciation

\footnotetext{
* Mestre pelo Programa Multi-institucional e Inter-regional de Pós-Graduação em Ciências Contábeis UnB, UFPB, UFPE e UFRN. Professora Assistente da Universidade Federal do Rio Grande do Norte (UFRN) - Centro de Ciências Sociais Aplicadas (CCSA) - Departamento de Ciências Contábeis (DCC). Endereço: Av. Senador Salgado Filho S/N - Lagoa Nova - Natal/Rio Grande do Norte - Brasil - CEP 59 072-970 -E-mail: patriciacosta@ufrnet.br.

** Doutor em Controladoria e Contabilidade pela Universidade de São Paulo. Professor Titular da Universidade de Brasília - Departamento de Ciências Contábeis e

Atuariais. Endereço: Campus Darcy Ribeiro Bloco FA - Sala Asa Norte - Brasília/DF - Brasil - CEP 70910-900 -. E-mail: tiburciosilva@aol.com 


\section{Introdução}

O impacto do avanço tecnológico nos custos hospitalares tem sido alvo de recentes debates na imprensa mundial (BALFOUR et al., 2004; BECKER, 2004; CAREY, 2003; HOF, 2003; VASSALO, 1997). Vassalo (1997) discute o trade-off existente entre qualidade e custo do tratamento médico, apontando o progresso tecnológico como a principal causa do aumento dos custos com serviços hospitalares. Hof (2003) afirma que o investimento em tecnologia será crescente e que esse cenário irá perdurar por muito tempo, alertando que o aumento da produtividade em decorrência do avanço tecnológico está condicionado ao controle de custos.

Em outro artigo, a revista Business Week trata da questão do preço dos medicamentos (CAREY, 2003). O autor do artigo revela que, nos EUA, os custos com pesquisa e desenvolvimento de novos medicamentos não são divididos proporcionalmente com os países desenvolvidos. Dessa forma, é possível encontrar naquele país, o antidepressivo Zoloft, por US\$82; enquanto no Canadá custa US\$42 e na França, US\$29. Essa diferença de preços entre países pode ser observada também nos tratamentos médicos. Segundo Balfour (2004), uma cirurgia do coração, com semelhante qualidade e feita por médicos renomados, pode custar US\$8.000 na Tailândia e US\$25.000 nos EUA. Conseqüentemente, na Tailândia, os médicos trataram, em 2002, mais de 308.000 pacientes, gerando receita da ordem de US\$280 milhões, enquanto a Índia espera alcançar uma receita de US\$1 bilhão com o "turismo da saúde". Essa discrepância de preços pode ser decorrente, segundo Baker (2001), da escala de atendimento adotada por alguns hospitais. De acordo com esse autor, a maioria dos hospitais adquire equipamentos de última geração sem analisar se a demanda é suficiente para pagar o investimento realizado.

Nos EUA, tem sido adotadas algumas iniciativas para um maior aproveitamento da capacidade dos equipamentos hospitalares. Por exemplo, utilizando-se unidades móveis que rodam vários hospitais $24 \mathrm{~h}$ por dia com um tomógrafo (BAKER, 2001); ou pela adoção, em alguns hospitais, do atendimento especialista em substituição ao generalista (STRUETT et al, 2002).

Apresentar os argumentos publicados na imprensa mundial tem o objetivo de tentar mostrar a preocupação com o aumento dos custos hospitalares, ocasionado especialmente pelo progresso tecnológico. Entretanto, esse assunto também tem sido discutido pela literatura científica (BAKER, 2001; BANTA e GELIJNS, 1987; BARBOSA e MALIK, 2003; BARNUM e KUTZIN, 1993; CHING, 2001; FALK, 2001; FOOTE, 1995; FUCHS, 1996).

A busca pela excelência tem sido apresentada por instituições hospitalares como justificativa para a falta de limites nos gastos com a prestação de serviços à sociedade (BOWEN, 1980). Isso conduz ao chamado "imperativo tecnológico", que significa adotar novas tecnologias, sem analisar os reais benefícios ou resultados que possam trazer aos pacientes (DOZET, LYTTKENS e NYSTEDT, 2002; FOOTE, 1995). Mendes (1984) explica que a capacidade de efetuar avaliações prévias é bastante limitada nos países periféricos, o que encarece o atendimento médico; daí a importância de se mensurar o quanto o impacto tecnológico é responsável por esse encarecimento. Segundo Marinho (2003), a construção de um hospital de 500 leitos, totalmente equipado, pode custar US\$250 milhões, 75\% desse total por conta dos equipamentos. Assim, o problema que se apresenta é saber qual o impacto do progresso tecnológico nos custos do tratamento hospitalar. É justamente esse o objetivo deste estudo.

\section{Fundamentação teórica}

McClellan e Noguchi (1998) dividem a inovação tecnológica em tratamentos low-tech e high-tech. As inovações high-tech demandam grande custo fixo ou marginal, enquanto as inovações low-tech demandam, relativamente, menores custos fixos e marginais, de modo que possam ser disponibilizadas por quase todo recurso médico. Para esses autores, conhecer as consequiências do avanço tecnológico no bem-estar do paciente e nos custos do tratamento, bem como distinguir os tipos de inovações, são importantes para o desenvolvimento de políticas que otimizem o tratamento médico e a difusão tecnológica. A difusão de uma tecnologia high-tech, 
por exemplo, deve ser precedida de uma avaliação do seu impacto nos custos, pela necessidade de investimentos no treinamento de funcionários, infra-estrutura, manutenção e benefícios, entre outros itens.

O trade-off entre custo e qualidade da assistência médica tem sido questionado por causa do aumento desse custo. Tullock (1995) afirma que esse aumento não ocorre por causa do encarecimento de alguns tratamentos, mas porque o progresso tecnológico tem significado a descoberta da cura de algumas doenças a um custo muito alto. De acordo com Mendes (1984), estima-se que, enquanto os investimentos aumentam em 100\%, as taxas de mortalidade e morbidade, em países desenvolvidos, diminuem apenas 5\%.

Fortes evidências indicam o chamado "imperativo tecnológico" (dar a todos os pacientes o melhor tratamento tecnologicamente possível) como forte direcionador do progresso tecnológico (DOZET, LYTTKENS e NYSTEDT, 2002). Segundo esses autores (p.52) "independentemente de ser visto como um imperativo profissional, um imperativo de viés de capital ou um imperativo da saúde, normalmente, implica forte incentivo para se adotar novas tecnologias".

O progresso tecnológico é fundamental na vida moderna, com relevância política crescente devido ao rápido aumento dos gastos com saúde (BARNUM e KUTZIN, 1993). A dependência da tecnologia aumenta a preocupação quanto aos seus riscos, benefícios, financiamento e implicações sociais (KLIGERMAN, 2001).

As pesquisas sobre o impacto do progresso tecnológico na área de saúde estão focadas nos fatores custo e benefício. Existem dois estudos (CUTLER e McCLELLAN, 2001; CUTLER, McCLELLAN e NEWHOUSE, 1998) que investigaram a relação custo/benefício no tratamento de doenças cardiovasculares. As análises consideram que os benefícios surgem à medida que inovações tecnológicas possibilitam prolongar a expectativa de vida do paciente. Com base em pesquisas realizadas nos EUA, os autores calculam uma despesa de US $\$ 25.000$ e US\$100.000, respectivamente - segundo a abordagem quality-adjusted life year (Qaly) - para cada ano de vida do paciente, após o tratamento. Cabe lembrar que o custo médio do tratamento foi estipulado a partir dos dados divulgados pelo Medicare. ${ }^{1}$

Este texto procura determinar o impacto da tecnologia no tratamento para litíase urinária, área na qual a importância do desenvolvimento tecnológico tem sido apontada em diversas pesquisas. No período 1999-2001, Varkarakis (2003) testou a resolubilidade de um aparelho de litotripsia, modelo Dornier L 50, em 130 pacientes gregos com cálculo proximal ureteral, que foram divididos em dois grupos. No primeiro grupo foram incluídos 65 pacientes submetidos a litotripsia. No segundo grupo, outros 65 pacientes submetidos a litotripsia após uma tentativa de retirada do cálculo urinário com auxílio de cateter ureteral. Um mês após o tratamento, a média de stone free ${ }^{2}$ foi de $83 \%$, para o grupo 1 , e de $95 \%$, para o grupo 2. A taxa de sucesso para o grupo 1 foi estatisticamente significante, mas relacionada a um custo maior ( $€ 852$ versus $€ 1.008)$.

Juntamente com outros estudiosos, Johnson (2003) testou a resolubilidade do equipamento de litotripsia modelo Dornier Doli S, nos EUA, em 270 pacientes atendidos no período 1998-2001. Desse total, 204 pacientes tinham cálculo renal e 66, cálculo ureteral. O tamanho médio do cálculo é de $9,7 \mathrm{~mm}$ e a média do cálculo ureteral foi de 7,8mm. No grupo renal, 176 (86\%) dos 204 pacientes tiveram sucesso clínico. Desses 176 pacientes, 148 tiveram stone free (73\%) e 28 tiveram fragmentos residuais menores que $4 \mathrm{~mm}$ (14\%). No grupo ureteral, dos 66 pacientes, 52 tiveram sucesso clínico, 50 dos quais tiveram stone free, sendo que dois deles tiveram fragmentos menores do que $4 \mathrm{~mm}$. Dos 204 pacientes, 13 no grupo renal e quatro dos 62 pacientes do grupo ureteral precisaram de novo tratamento.

Ao analisar a relação custo/benefício, Lotan (2002) apurou um gasto de US\$4.225 com a litotripsia e US\$2.645 com a ureteroscopia. O benefício foi estimado numa taxa de sucesso de $97 \%$ para a ureteroscopia e de $75 \%$ para a litotripsia.

\footnotetext{
${ }^{1} \mathrm{O}$ Medicare é um programa do governo americano que dá cobertura a pessoas com mais de 65 anos e a pessoas mais jovens com certas disfunções (ANTONY e GOVINDARAJAN, 2001). O reembolso é realizado com base em tabelas de preço com valores fixos para cada tratamento.
}

${ }^{2} \mathrm{O}$ diagnóstico stone free indica que todos os cálculos do paciente foram eliminados; ou seja, que o tratamento foi totalmente eficaz. 
Street (1993) e Cook, Richardson e Street (1994) calcularam as despesas com alternativas de tratamento de cálculo urinário, incluindo o custo hospitalar total (médicos, hospedagem, exames, enfermeiros, gastos indiretos, medicamentos e depreciação) e as despesas do paciente (incluindo tempo de transporte e viagem e custos de viagem, transporte e estadia do paciente e seus familiares). Os estudos desses autores apuraram que o custo hospitalar médio da cirurgia aberta, da cirurgia endoscópica e da litotripsia é de US\$3.366, US\$2.699 e US\$4.617, respectivamente. Incluindo os custos indiretos e os custos do paciente, o gasto total de cada tratamento sobe para US\$6.922, US\$4.422 e US\$5.536, respectivamente. Assim, com base somente nos custos hospitalares, a litotripsia é a mais cara das três opções de tratamento, mas, considerados os gastos com o paciente, tem custo inferior ao da cirurgia aberta. A razão disso é que na cirurgia aberta, há necessidade de internação por um prazo médio de 15 dias após a cirurgia; enquanto a litotripsia requer do paciente repouso, em média, de apenas dois dias, após o procedimento, na sua própria casa.

No cálculo dos benefícios de cada tratamento, aspectos subjetivos e, às vezes, contraditórios surgem nas pesquisas anteriormente apresentadas. A estimativa do valor para cada ano a mais de vida do paciente, após a realização do tratamento para doenças cardíacas, varia de US\$25.000 (CUTLER, McCLELLAN e NEWHOUSE, 1998) a US $\$ 100.000$ (CUTLER e McCLELLAN, 2001), indicando a necessidade de mais pesquisas sobre $\mathrm{o}$ assunto.

Para os procedimentos de litotripsia, foi apurada uma resolubilidade de $83 \%$ e $95 \%$, em períodos distintos (VARKARAKIS et al, 2003), 86\% (JOHNSON et al, 2003) e 75\% (LOTAN et al, 2002). Tais divergências podem ser resultado da utilização de diferentes métodos de apuração do benefício e/ou da utilização de diferentes modelos de aparelhos de litotripsia. Conforme destaca Johnson (2003), cada litotritor deve ser avaliado individualmente com relação à eficácia do tratamento.

Quanto ao levantamento do custo dos tratamentos, percebe-se nos estudos apresentados o uso incorreto da variável receita - por exemplo, o reembolso do Medicare - (CUTLER, McCLELLAN e NEWHOUSE, 1998; CUTLER e McCLELLAN, 2001; VARKARAKIS et al, 2003) como proxy de custo. Outros estudos, como os de Brown (2000) e de Brandon (2002), misturam as fontes para estimativa de custo, utilizando dados de receita (o Medicare como base de dados para procedimentos ambulatoriais) e algumas estimativas de custo realizadas por outros órgãos (o Drug Topics Red Book como base de dados para custos de medicamentos) para determinar o gasto com os tratamentos para catarata. Tais fatos podem ser conseqüência da dificuldade de se conseguir informações sobre custo.

\section{0 caso do tratamento para litíase urinária}

O estudo de caso foi realizado na área de litotripsia e no centro cirúrgico do Centro de Imagenologia do Hospital Universitário de Brasília (HUB). O serviço de litotripsia desse hospital foi implantado com a aquisição do equipamento de litotripsia, e presta um serviço único. O HUB é um hospital geral de grande porte, com 302 leitos ativos (BRASIL, 2004), onde são efetuadas, anualmente, cerca de 200.000 consultas, 10.000 internações, 5.000 cirurgias, 1.500 partos, 900.000 exames e 70.000 procedimentos odontológicos. O hospital tem um programa de residência médica em 18 especialidades, para 80 residentes. Além disso, o HUB é campo de ensino para cerca de 100 alunos de pós-graduação e 2.300 de graduação; com um quadro de mais de 2.000 funcionários e servidores

Com relação à área médica escolhida, cabe destacar o impacto social da calculose urinária, na população mundial. O risco de se sofrer de cálculos, em algum momento da vida, é da ordem de $5 \%$ a $20 \%$, com um índice de recorrência de 50\%, em cinco anos, o que gerou, em 1993, um custo de US\$3 bilhões, nos EUA, englobando diagnóstico, tratamento e prevenção da litíase urinária (CHAMBÔ, 2004). Nesse país, de cada 1.000 internações, sete a 10 são causadas pela litíase (ALMEIDA e SCHOR, 2001). O pico de incidência da calculose urinária é na faixa dos 30 aos 50 anos, e a ocorrência é maior nos homens do que nas mulheres, na proporção de 3 por 1 (CHAMBÔ, 2004; SCHOR e HEILBERG, 2004). Na Espanha, para uma expectativa de vida de 70 anos, calcula-se em cerca de $15 \%$ a probabilidade de incidência de cálculo urinário (GARCIA, 2002) . Nesse país, anualmente, a incidência esperada é de sete a 21 casos por cada 10.000 habitantes. 
Nos países industrializados, os casos de litíase urinária vem aumentando, enquanto nos países em desenvolvimento, atinge de $10 \%$ a $15 \%$ da população (ALMEIDA e SCHOR, 2001). A incidência da litíase urinária é especialmente complexa num país de dimensões continentais como o Brasil, cujas condições climáticas e os hábitos alimentares variam muito. sendo que a incidência média de litíase urinária no país varia em torno de 5\% a 10\%. (SCHOR e HEILBERG, 2004).

A partir desses valores históricos é possível definir o potencial de atendimento médico nessa área. Considerando a estimativa máxima da Espanha - 21 casos de litíase urinária, anualmente, para cada 10.000 habitantes - pode-se estimar a demanda máxima por tratamento da calculose urinária no Distrito Federal (DF), local onde fica o Hospital Universitário de Brasília. Dos 2.051.146 habitantes do Distrito Federal (IBGE, 2000), 4.307 têm chance de sofrer de calculose urinária. Num caso extremo de se dispor apenas do procedimento de litotripsia para tratamento desse total de pacientes com litíase urinária - média de duas sessões por paciente, 52 semanas por ano, e capacidade máxima, por equipamento, de 15 sessões diárias -, chega-se ao total de 3.900 sessões anuais por equipamento e a uma demanda total de 8.614 sessões. Assim, seriam necessários, no máximo, três equipamentos de litotripsia para atender à população do Distrito Federal.

Tradicionalmente, a cirurgia é o tratamento para sintomas de calculose urinária. A litotripsia extracorpórea por ondas de choque (Leco) - extra corporeal shockwave lithotripsy (ESWL) - é uma nova opção para tratamento de litíase urinária de forma não-invasiva, em que os cálculos são fragmentados por ondas de choque. A triagem clínica para ambos os procedimentos é apresentada na figura 1.

\section{Figura 1}

\section{Algoritmo semiológico e terapêutico da litíase de cálculo urinário no HUB}

\begin{tabular}{|c|}
\hline \multicolumn{1}{|c|}{$1^{\text {a }}$ Consulta (1) } \\
\hline \multicolumn{2}{|c|}{ Exames (2) } \\
$\begin{array}{c}\text { Laboratório: hemograma completo + tempo de coagulação e } \\
\text { sangramento, uréia, creatinina, glicose e urocultura; }\end{array}$ \\
Imagem: radiografia simples de abdome e ecografia do trato urinário. \\
\hline Retorno (3) \\
Tomada de decisão com base nos exames, idade do paciente, tamanho do \\
cálculo, análise do rim e no tipo físico.
\end{tabular}

\section{Não tratamento \\ Acompanhamento com remédio e}

ingestão de líquidos (quando o cálculo é muito pequeno).

\section{Cirurgia}

Indicações: rim doente, paciente obeso, antecedentes de litotripsia sem sucesso, coagulação, gravidez e obstrução ou infecção urinária;

Internação $24 \mathrm{~h}$ antes da data da cirurgia.

Tipos de cirurgia: renal aberta (RA), begixa aberta (BA), ureteral aberta (UA), renal percutânea (RP), bexiga percutânea (BP) e ureteral percutânea (UP)

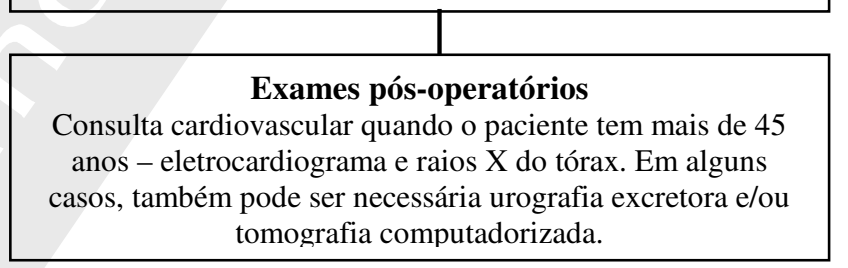
tomografia computadorizada. 
A litotripsia não substitui totalmente a cirurgia. A opção por um ou outro procedimento dependerá de uma análise conjunta de vários fatores, tais como (JOHNSON et al, 2003; LOTAN et al, 2002):

- resultados dos exames de laboratório e imagem;

- situação clínica do paciente; por exemplo, gravidez, falha de tratamentos anteriores, infecção e/ou obstrução urinária persistente;

- idade;

- tamanho, localização e composição do cálculo;

- análise do rim e tipo físico do paciente;

- preferência do paciente;

- disponibilidade de equipamento;

- habilidade do cirurgião e

- custos do tratamento.

A Portaria Conjunta n⿳ 47 , assinada pelo Ministério da Saúde e pelo Departamento de Endourologia da Sociedade Brasileira de Urologia, indica a litrotripsia para pacientes com cálculo menor que 2,5cm (BRASIL, 2001). Entretanto, o HUB efetua o controle classificando o tamanho dos cálculos em maior ou menor do que $2 \mathrm{~cm}$; classificação esta que foi a adotada neste estudo.

O cálculo urinário pode estar localizado no rim, no ureter, na bexiga ou na vesícula. As cirurgias para o tratamento do problema podem ser classificadas em: renal aberta (RA), renal percutânea (RP), bexiga aberta (BA), bexiga percutânea (BP), ureteral percutânea (UP) e ureteral aberta (UA), conforme a localização e o tamanho do cálculo. A principal distinção entre a cirurgia "aberta" e a "percutânea" é o tamanho da incisão. Na cirurgia aberta, a incisão é de aproximadamente $10 \mathrm{~cm}$, enquanto na cirurgia percutânea a incisão é de cerca de $1 \mathrm{~cm}$. Neste estudo, os tipos de cirurgia serão agrupados em três categorias devido à similaridade das atividades e dos custos: RA (incluindo as categorias RA, BA e UA); RP e UP (incluindo as categorias UP, BP). Os procedimentos de litotripsia são todos percutâneos, pois não necessitam de incisão e são realizados de forma não-invasiva.

Para estudar o impacto do progresso tecnológico no tratamento hospitalar será feita uma análise do custo/benefício da incorporação de um aparelho médico usado no tratamento urinário, denominado litotritor. $\mathrm{O}$ litotritor Dornier HM3 foi o primeiro aparelho aprovado pela Food and Drug Administration (FDA), nos EUA, para tratamento de litíase urinária (EVAN et al, 2004). Ele recorre ao procedimento extracorpóreo de ondas de choque por descarga elétrica (outros modelos incluem geradores eletromagnéticos e piezelétrico) debaixo d'água, para fragmentar os cálculos, sem nenhuma incisão (ibidem). Desde que esse aparelho foi lançado no mercado, em dezembro de 1984, mais de 40 tipos de aparelhos de litotripsia foram comercializados em todo o mundo (ibidem).

O avanço tecnológico dos litotritores foi baseado, principalmente, na melhoria do sistema de imagem dos cálculos (que são visualizados por meio de um aparelho de radiografia que é parte do litotritor), no desenvolvimento de aparelhos que podem ser utilizados como litotritores ou mesa de cirurgia para litíase urinária, e na tentativa de proporcionar mais conforto aos pacientes, reduzindo a necessidade de anestesia geral (EVAN et al, 2004).

Os litotritores também têm sido desenvolvidos para atuarem em apenas um pequeno ponto focal, para reduzir o número de ondas de choque necessárias à pulverização do cálculo e, ainda, para reduzir o risco de efeitos colaterais. Essa estratégia também tem demonstrado, em práticas clínicas, ser menos efetiva do que outras tecnologias. Em geral, com litotritores menos robustos, com foco em pontos de menor abrangência, conseguese menores taxas de stone free e/ou maiores taxas de novo tratamento. Quando o paciente é anestesiado, é possível conseguir uma melhor taxa de stone free com esses aparelhos, sugerindo que uma redução dos 
movimentos principais do paciente permitirá aplicar mais pancadas diretas das ondas de choque nos cálculos (EVAN et al, 2004).

\section{Mensuração do impacto do progresso tecnológico nos custos da litíase urinária}

Para estudar o impacto da tecnologia, aqui, irá se recorrer à análise diferencial. Basicamente, esta propõe que, diante de duas ou mais alternativas, quem toma a decisão opte por aquela que ofereça maior lucratividade incremental ou menor custo decremental (DILLON e NASH, 1978). As expressões "custos diferenciais", "custos incrementais" e "custos relevantes" são, com freqüência, empregadas indistintamente, ainda que existam algumas diferenças de ordem técnica (GARRISON e NOREEN, 2001). Os custos relevantes são os esperados custos futuros que se tornam diferentes em linhas de ação alternativas. $\mathrm{O}$ custo diferencial é a diferença entre os custos relevantes de duas ou mais alternativas. $\mathrm{O}$ resultado dessa diferença pode ser um aumento (denominado custo incremental) ou uma redução (custo decremental) nos custos de uma alternativa em relação à outra. Assim, o custo diferencial é um termo que engloba tanto os custos incrementais, quanto os decrementais.

Os conceitos da análise diferencial podem ser aplicados para avaliar a relação custo/benefício de diversas decisões no curto prazo (DILLON e NASH, 1978; INNES e MITCHELL, 1993; VATTER, 1945). Para esses autores, tais decisões envolvem alterações no mix de produto, no nível de estoque, no processo de privatização, no planejamento de capacidade e na escolha entre comprar ou fazer e aceitar ou recusar encomendas especiais. Essas decisões "provocam um efeito imediato no nível de produção e, consequientemente, nos custos diretamente afetados pela produção" (INNES e MITCHELL, 1993, p.25), sendo que os efeitos podem ser sentidos tanto nos custos variáveis quanto nos custos fixos. As alterações em custos variáveis e fixos são provocadas por mudanças no volume e na capacidade, respectivamente.

Situações como a de decidir investir em novas tecnologias envolvem um processo complexo que compara resultados clínicos atuais com aqueles prometidos pela nova tecnologia. Às vezes, a informação sobre os custos diferenciais pode ser um fator-chave na hora de decidir sobre a compra de novas tecnologias (INGRAM, ALBRIGHT e HILL, 1997).

Foram apurados os custos e as receitas relevantes entre as alternativas de tratamento. Conforme a figura 1, os itens 1,2 e 3 são idênticos, independentemente do procedimento. Assim, esses custos foram considerados irrelevantes na análise diferencial.

Para realização da pesquisa foram coletados dados dos pacientes atendidos no centro cirúrgico e no serviço de litotripsia do HUB, para tratamento de cálculo urinário, no período 2001-03. Esse foi o período escolhido para a pesquisa por causa da data em que o aparelho de litotripsia foi incorporado ao acervo patrimonial do hospital.

As bases de dados para a identificação das litotripsias foram os "livros de litotripsia". Neles foram averiguados os seguintes dados: data da sessão, nome do paciente e número do prontuário médico. Para levantar os demais dados (sexo, procedência, idade, tamanho do cálculo, número de impulsos e categoria) foi preciso consultar o prontuário ${ }^{3}$ de cada paciente.

Foram estabelecidos padrões ou protocolos de atendimento para cada tipo de procedimento. Para estabelecer os padrões, recorreu-se aos relatórios de planejamento e controle do HUB e foram feitas entrevistas nãoestruturadas com os profissionais envolvidos. O estabelecimento de um padrão de custo para cada categoria de cirurgia para calculose urinária compreendeu os custos do período pré-operatório (o paciente é internado 24 horas antes da cirurgia), os custos da cirurgia e os custos do período pós-operatório.

O prazo médio de permanência (PMP), para cada categoria de cirurgia, foi estimado a partir dos dados obtidos nos prontuários dos pacientes atendidos, durante o período estudado. A soma dos PMPs de cada categoria de cirurgia foi dividida pela quantidade de pacientes, resultando num PMP para cada categoria de cirurgia. As

${ }^{3}$ A realização da pesquisa no HUB foi aprovada por parecer do Comitê de Ética em Pesquisa da Faculdade de Medicina (CEP-FM) da Universidade de Brasília. 
complicações cirúrgicas podem aumentar excessivamente o PMP do paciente. Nesse caso, os outliers foram excluídos da análise. Para saber o gasto diário de internação do paciente, os procedimentos foram os mesmos adotados para identificar os custos pré-operatórios.

A vida útil (física e funcional) e o consumo de água e energia do litotritor foram estimados com base em informações dos técnicos representantes da Dornier no Brasil, fabricante do equipamento. Foi utilizada a capacidade prática para alocação da depreciação e foi identificado o tempo necessário para set up em cada tipo de procedimento. Para cálculo das capacidades teórica e prática foi considerado que o serviço de litotripsia opera oito horas por dia, cinco dias na semana, e que cada ano tem 52 semanas.

Para analisar o impacto do progresso tecnológico nos custos do tratamento, foram calculados os gastos e os benefícios diferenciais para quatro alternativas de decisão:

- manter o status quo - o hospital poderia não investir no equipamento de litotripsia e manter em $2002 \mathrm{e}$ em 2003, a mesma quantidade e o mesmo mix de cirurgias feitas em 2001;

- incrementar o procedimento de cirurgia - aumentar o número de horas e salas de cirurgias disponíveis para as cirurgias de cálculo urinário para os anos de 2002 e 2003, como também a quantidade de médicos. Essa decisão foi implementada no HUB. Dessa forma, para o cálculo dos custos e benefícios dessa possibilidade foi utilizada a quantidade de cirurgias realizadas em 2002 e 2003;

- oferecer apenas o procedimento de cirurgia, mas atender a toda a demanda dos pacientes com diagnóstico de cálculo urinário. O hospital não investiria na compra do equipamento de litotripsia; ofereceria apenas a opção de cirurgia para tratamento de cálculo urinário. Porém, atenderia toda os pacientes submetidos às duas opções de tratamento em 2002 e 2003;

- litotripsia e cirurgia - utilizar tais procedimentos para o tratamento de calculose urinária. Foram consideradas as quantidades efetivamente realizadas no HUB de cada procedimento em 2002 e 2003.

A importância da tecnologia será medida pela instalação no hospital, de um equipamento da marca Dornier Medtech, modelo Dornier Lithotripter S, de origem alemã, cujo valor em 31-12-2003 equivalia a $\mathrm{R} \$ 2.384 .207,22$, com 36 meses de garantia. O equipamento é composto por um gerador de ondas de choque, mesa de paciente, sistema de raios X e ultra-som, painel de comando e acessórios para uso em litotripsia, cistoscópio, cateterismo urológico e diagnóstico. Em maio de 2004, técnicos representantes da Dornier no Brasil estimaram em 15 anos a vida útil física e em 10 anos a vida útil funcional do litotritor. $\mathrm{O}$ valor residual foi estimado em aproximadamente $10 \%$ do valor corrente de um equipamento. Segundo esses técnicos, a capacidade máxima diária de realização do procedimento de litotripsia é de 16 sessões, com frequiência de 80 a 100 impulsos por minuto (considerando uma carga horária de trabalho de 40 horas semanais). Nos prontuários médicos do HUB foi verificado que a quantidade média de impulsos por sessão de litotripsia é de 3.000 impulsos, com freqüência de 80 a 100 impulsos por minuto. Portanto, em média, cada sessão dura 30 minutos (sem considerar o tempo de set-up).

O hospital realizou 500 sessões de litotripsia no período 2002-03, conforme tabela 1. 
Tabela 1

Quantidade total e média de sessões de litotripsia e número de pacientes

por tamanho de cálculo - 2002 e 2003

\begin{tabular}{|c|c|c|c|c|c|c|c|}
\hline \multirow[b]{2}{*}{ Tamanho do cálculo } & \multicolumn{2}{|c|}{$\begin{array}{c}\text { Quantidade de sessões } \\
\text { (1) }\end{array}$} & \multicolumn{2}{|c|}{$\begin{array}{l}\text { Quantidade de } \\
\text { pacientes }(2)\end{array}$} & \multicolumn{2}{|c|}{$\begin{array}{c}\text { Quantidade média de } \\
\text { sessões (1)/(2) }\end{array}$} & \multirow{2}{*}{$\begin{array}{l}\text { Total de } \\
\text { sessões }\end{array}$} \\
\hline & 2002 & 2003 & 2002 & 2003 & 2002 & 2003 & \\
\hline Menor que $2 \mathrm{~cm}$ & 112 & 267 & 58 & 151 & 1.93 & 1.77 & 379 \\
\hline Maior que $2 \mathrm{~cm}$ & 19 & 41 & 10 & 21 & 1.90 & 1.95 & 60 \\
\hline Sem tamanho & 13 & 17 & 5 & 11 & 2.60 & 1.55 & 30 \\
\hline Sem prontuário & 10 & 21 & 7 & 19 & 1.43 & 1.11 & 31 \\
\hline Total & 154 & 346 & 80 & 202 & 1.93 & 1.71 & 500 \\
\hline
\end{tabular}

Fonte: elaborada pelos autores, com base em livros de litotripsia e nos prontuários.

A maior incidência de calculose urinária ocorreu em mulheres $-53 \%$, nos dois períodos estudados. Esse resultado diverge do verificado nos estudos de Chambô (2004) e Schor e Heilberg (2004) - onde é consta maior incidência em homens, na proporção de 3 para 1. A incidência de cálculo urinário no tratamento por litotripsia é de $79 \%$, para cálculo renal, e $21 \%$, para cálculo ureteral.

Para determinar a receita foi utilizado o valor do reembolso do Sistema Único de Saúde (SUS) para a litotripsia, baseado na quantidade de impulsos. O SUS reembolsa $\mathrm{R} \$ 172,00$ para cada 700 impulsos - no intervalo de 0 a 2.800 impulsos aplicados em cada sessão, e $\mathrm{R} \$ 150,50$ para cada 700 impulsos - no intervalo de 2.801 a 5.600 impulsos aplicados em cada sessão. Como a média de impulsos de cada sessão no hospital é de 3.000, o reembolso médio do SUS é de R $\$ 752,50$ por sessão. Esse valor é acrescido de $\mathrm{R} \$ 14,84$ nos casos em que o paciente necessita de analgesia. Além disso, o Ministério da Saúde, por meio do Fator de Incentivo ao Desenvolvimento de Ensino e Pesquisa em Saúde (Fideps), diferencia o reembolso aos hospitais universitários, por incorporarem atividades de ensino e pesquisa. Analisando os relatórios gerenciais verificou-se um aumento médio de cerca de $21 \%$ no faturamento do SUS, durante no período 2001-03. Assim, nesta pesquisa, foi considerado o reembolso de $\mathrm{R} \$ 910,53$, para cada sessão de litotripsia, e de $\mathrm{R} \$ 928,48$, para cada sessão de litotripsia com aplicação de analgesia.

Importante componente na análise, o custo da mão-de-obra foi levantado pela estimativa do tempo gasto pelos médicos e enfermeiros, incluindo o tempo de preparação, que envolve a troca de lençol, vestir o pijama, posicionar o paciente na mesa do litotritor, a prescrição da conduta do paciente, colocar o gel, localizar o cálculo e a aplicação de analgesia. A esse tempo foi associado o valor do salário, com base na folha de pagamento. $\mathrm{O}$ custo unitário da mão-de-obra foi multiplicado pela quantidade de sessões realizadas a cada ano, resultando no custo anual com mão-de-obra. Também foi feito o levantamento do custo de material médico e administrativo e de medicamentos, de telefone, energia e água e de depreciação.

A depreciação do equipamento, da capacidade não utilizada e da provisão para obsolescência estão indicadas na tabela 2. Para determinar a capacidade não utilizada foi relacionada a utilização efetiva do equipamento, em cada ano de análise, com sua capacidade de atendimento. $\mathrm{O}$ valor da depreciação foi obtido, deduzindo-se do custo do equipamento $(\mathrm{R} \$ 2.384 .207,22)$ o valor residual $(\mathrm{R} \$ 238.420,72)$ e dividindo a vida útil do mesmo. 
Tabela 2

Cálculo da depreciação do litotritor, da capacidade não utilizada

e da provisão para obsolescência

\begin{tabular}{|c|c|c|c|c|c|}
\hline \multirow[b]{2}{*}{ DADOS } & \multicolumn{2}{|c|}{2002} & \multicolumn{2}{|c|}{2003} & \multirow[t]{2}{*}{ Total } \\
\hline & $\mathbf{A P}$ & PÓS-AP & $\mathbf{A P}$ & PÓS-AP & \\
\hline a) Turno semanal (40h x 60min) & 2,400 & 2,400 & 2,400 & 2,400 & \\
\hline b) Número de semanas & 8.67 & 26.00 & 8.67 & 43.33 & \\
\hline c) Turno do período ( $\mathrm{a} \times \mathrm{b}$ ) & 20,800 & 62,400 & 20,800 & 104,000 & \\
\hline d) Vida útil física - anual & 15 & 15 & 15 & 15 & \\
\hline e) Vida útil funcional - anual & 10 & 10 & 10 & 10 & \\
\hline $\begin{array}{l}\text { f) Base de cálculo vida útil física } \\
((\mathrm{R} \$ 2.145 .786,50 / \mathrm{d}) / 52 * \mathrm{~b})\end{array}$ & $\mathrm{R} \$ 23,842.07$ & $\mathrm{R} \$ 71,526.22$ & $\mathrm{R} \$ 23,842.07$ & $\mathrm{R} \$ 119,210.36$ & $\mathrm{R} \$ 238,420.72$ \\
\hline $\begin{array}{l}\text { g) Base de cálculo - vida útil funcional } \\
((\mathrm{R} \$ 2.145 .786,50 / \mathrm{e}) / 52 * \mathrm{~b})\end{array}$ & $\mathrm{R} \$ 35,763.11$ & $\mathrm{R} \$ 107,289.33$ & $\mathrm{R} \$ 35,763.11$ & $\mathrm{R} \$ 178,815.54$ & $\mathrm{R} \$ 357,631.08$ \\
\hline h) Manutenção preventiva- min. & 1,440 & 1,920 & 1,440 & 5,760 & 10,560 \\
\hline i) Duração da sessão & 60 & 30 & 60 & 30 & \\
\hline j) Setup & 30 & 5 & 30 & 5 & \\
\hline $\begin{array}{l}\text { k) Número de sessões ano - capacidade } \\
\text { prática }((\mathrm{c}-\mathrm{h}) /(\mathrm{i} \text { PÓS-AP+ j PÓS-AP) })\end{array}$ & 553 & 1,728 & 553 & 2,807 & \\
\hline $\begin{array}{l}\text { 1) Número de sessões ano - capacidade } \\
\text { Normal }\end{array}$ & 20 & 134 & 34 & 312 & \\
\hline $\begin{array}{l}\text { m) Número de sessões dia - capacidade } \\
\text { prática (g/número de semanas/5) }\end{array}$ & 12.76 & 13.29 & 12.76 & 12.95 & \\
\hline $\begin{array}{l}\text { n) Número de sessões dia - capacidade } \\
\text { prática }(\mathrm{g} / \text { número semanas/5) }\end{array}$ & 0.46 & 1.03 & 0.78 & 1.44 & \\
\hline o) Depreciação por sessão (f / k) & $\mathrm{R} \$ 43.10$ & $\mathrm{R} \$ 41.39$ & $\mathrm{R} \$ 43.10$ & $\mathrm{R} \$ 42.47$ & \\
\hline p) Depreciação total (1 x o ) & $\mathrm{R} \$ 862.06$ & $\mathrm{R} \$ 5,546.59$ & $\mathrm{R} \$ 1,465.50$ & $\mathrm{R} \$ 13,250.99$ & $\mathrm{R} \$ 21,125.14$ \\
\hline $\begin{array}{l}\text { q) Capacidade não-utilizada((f / l)-(f / k )) } \\
\text { x l) }\end{array}$ & $\mathrm{R} \$ 22,980.01$ & $\mathrm{R} \$ 65,979.62$ & $\mathrm{R} \$ 22,376.57$ & $\mathrm{R} \$ 105,959.37$ & $\mathrm{R} \$ 217,295.58$ \\
\hline $\begin{array}{l}\text { r) Provisão para obsolescência }((\mathrm{g} / \mathrm{k}) \text { - } \\
(\mathrm{f} / \mathrm{k}) \mathrm{x} \text { k) }\end{array}$ & $\mathrm{R} \$ 11,921.04$ & $\mathrm{R} \$ 35,763.11$ & $\mathrm{R} \$ 11,921.04$ & $\mathrm{R} \$ 59,605.18$ & $\mathrm{R} \$ 119,210.36$ \\
\hline
\end{tabular}

Fonte: elaborada pelos autores.

O equipamento de litotripsia pode ser instalado em uma sala de cirurgia ou numa sala construída especialmente para esse fim. O hospital optou pela construção da sala. As instalações custaram $\mathrm{R} \$ 104.253,14$. A vida útil estimada da sala é de 25 anos, ${ }^{4}$ com um valor residual de $10 \%$. O cálculo da depreciação e a capacidade não utilizada estão na tabela 3 .

\footnotetext{
${ }^{4}$ Informações conseguidas na Divisão de Engenharia Clínica do HUB, em janeiro de 2004.
} 
Tabela 3

Cálculo da depreciação da sala de litotripsia e da capacidade não utilizada

\begin{tabular}{|c|c|c|c|c|}
\hline \multirow[b]{2}{*}{ DESCRIÇÃO } & \multicolumn{2}{|c|}{2002} & \multicolumn{2}{|c|}{2003} \\
\hline & $\mathbf{A P}$ & PÓS-AP & $\mathbf{A P}$ & PÓS-AP \\
\hline a) Número de semanas & 8.67 & 26.00 & 8.67 & 43.33 \\
\hline b) Base de cálculo ( $\mathrm{R} \$ 93.827,83$ / 52 / $25 \mathrm{x}$ a) & $\mathrm{R} \$ 625.52$ & $\mathrm{R} \$ 1,876.56$ & $\mathrm{R} \$ 625.52$ & $\mathrm{R} \$ 3,127.59$ \\
\hline c) Número de sessões - capacidade prática & 553 & 1,728 & 553 & 2,807 \\
\hline d) Número de sessões - capacidade normal & 20 & 134 & 34 & 312 \\
\hline e) Depreciação por sessão (b / c) & $\mathrm{R} \$ 1.13$ & $\mathrm{R} \$ 1.09$ & $\mathrm{R} \$ 1.13$ & $\mathrm{R} \$ 1.11$ \\
\hline p) Depreciação total $(\mathrm{d}$ x e $)$ & $\mathrm{R} \$ 22.62$ & $\mathrm{R} \$ 145.52$ & $\mathrm{R} \$ 38.45$ & $\mathrm{R} \$ 347.65$ \\
\hline q) Capacidade não-utilizada ((b / d)-(b / c)) x d) & $\mathrm{R} \$ 602.90$ & $\overline{\mathrm{R} \$ 1,731.04}$ & $\mathrm{R} \$ 587.07$ & $\overline{\mathrm{R} \$ 2,779.94}$ \\
\hline
\end{tabular}

Fonte: elaborada pelos autores.

A tabela 4 apresenta os resultados dos procedimentos de litotripsia realizados em 2002 e 2003, levando em conta custos e receitas. O resultado 1 é positivo em $\mathrm{R} \$ 287.922,48$. Entretanto, com a inclusão das despesas com capacidade não utilizada e a provisão para obsolescência, esse valor cai para $\mathrm{R} \$ 58.006,68$ negativo. Portanto, o valor da despesa com capacidade não utilizada e provisão para obsolescência é relevante na totalização dos custos.

\section{Tabela 4}

Resultados da litotripsia - período 2002-03

\begin{tabular}{|c|c|c|c|c|c|c|}
\hline \multirow[b]{2}{*}{ DESCRIÇÃO } & \multicolumn{3}{|c|}{2002} & \multicolumn{3}{|c|}{2003} \\
\hline & AP & PÓS-AP & Total & AP & PÓS-AP & Total \\
\hline 1) Receita & $18,210.50$ & $122,136.04$ & $140,346.54$ & $30,957.85$ & $284,514.75$ & $315,472.60$ \\
\hline \multicolumn{7}{|l|}{ Custos } \\
\hline Mão-de-obra & $1,943.39$ & $6,765.57$ & $8,708.96$ & $3,303.76$ & $15,919.57$ & $19,223.33$ \\
\hline MMAM & 154.20 & $1,033.14$ & $1,187.34$ & 262.14 & $2,405.52$ & $2,667.66$ \\
\hline Telefone, água e energia & $4,577.20$ & $30,667.24$ & $35,244.44$ & $7,781.24$ & $71,404.32$ & $79,185.56$ \\
\hline Depreciação do litotritor & 862.06 & $5,546.59$ & $6,408.65$ & $1,465.50$ & $13,250.99$ & $14,716.49$ \\
\hline Depreciação predial & 22.62 & 145.52 & 168.14 & 38.45 & 347.65 & 386.10 \\
\hline 2) Total do custo & $7,559.47$ & $44,158.06$ & $51,717.53$ & $12,851.09$ & $103,328.05$ & $116,179.14$ \\
\hline 3) Resultado 1 (1 - 2) & $10,651.03$ & $77,977.98$ & $88,629.02$ & $18,106.76$ & $181,186.70$ & $199,293.46$ \\
\hline \multicolumn{7}{|l|}{ Despesas } \\
\hline Provisão para obsolescência & $11,921.04$ & $35,763.11$ & $47,684.14$ & $11,921.04$ & $59,605.18$ & $71,526.22$ \\
\hline Capacidade não utilizada - litotritor & $22,980.01$ & $65,979.62$ & $88,959.64$ & $22,376.57$ & $105,959.37$ & $128,335.95$ \\
\hline Capacidade não utilizada - mão-de-obra & & & $4,424.05$ & & & $4,999.47$ \\
\hline 4) Total de despesas & $34,901.05$ & $101,742.73$ & $141,067.84$ & $34,297.61$ & $165,564.55$ & $204,861.63$ \\
\hline 5) Total custo + despesas $(2+3)$ & $42,460.52$ & $145,900.79$ & $192,785.36$ & $47,148.70$ & $268,892.60$ & $321,040.77$ \\
\hline 6) Resultado 2 (1 - 5) & $(24,250.02)$ & $(23,764.75)$ & $(52,438.82)$ & $(16,190.85)$ & $15,622.15$ & $(5,568.17)$ \\
\hline
\end{tabular}

Fonte: elaborada pelos autores.

No HUB, foram realizadas 125 cirurgias para calculose urinária no período 2001-03, quando foram atendidos 112 pacientes; sendo que 17 cirurgias não puderam ser consideradas no estudo pela falta de informações nos prontuários médicos (tabela 5). 
Tabela 5

Quantidade de cirurgias realizadas no HUB por tamanho de cálculo

\begin{tabular}{|c|c|c|c|c|c|c|c|c|c|}
\hline \multirow[b]{3}{*}{ Categorias } & \multicolumn{9}{|c|}{ QUANTIDADE POR TAMANHO DE CÁLCULO } \\
\hline & \multicolumn{3}{|c|}{ Menor que $2 \mathrm{~cm}$} & \multirow[b]{2}{*}{ Total } & \multicolumn{3}{|c|}{ Maior que $2 \mathrm{~cm}$} & \multirow[b]{2}{*}{ Total } & \multirow{2}{*}{$\begin{array}{l}\text { Total } \\
\text { geral }\end{array}$} \\
\hline & 2001 & 2002 & 2003 & & 2001 & 2002 & 2003 & & \\
\hline RA & 3 & 6 & 5 & 14 & 9 & 8 & 6 & 23 & 37 \\
\hline $\mathrm{RP}$ & - & 1 & 15 & 16 & 2 & 3 & 17 & 22 & 38 \\
\hline UP & 5 & 10 & 12 & 27 & 0 & 4 & 2 & 6 & 33 \\
\hline Total & 8 & 17 & 32 & 57 & 11 & 15 & 25 & 51 & 108 \\
\hline
\end{tabular}

Fonte: livros de cirurgia e prontuários médicos.

A tabela 6 apresenta a duração média do tratamento para calculose urinária por cirurgia, em minutos. O tamanho do cálculo tem implicação apenas na duração da cirurgia tipo RP. O custo total do período préoperatório foi obtido pela relação entre a duração da cirurgia e os recursos necessários para a sua realização.

\section{Tabela 6}

Duração e PMP por classificação de cirurgia e tamanho de cálculo

\begin{tabular}{lcccc}
\hline & \multicolumn{2}{c}{ Menor que 2cm } & \multicolumn{2}{c}{ Maior que 2cm } \\
\cline { 2 - 5 } Categoria & Duração (minutos) & PMP (dias) & Duração (minutos) & PMP (dias) \\
\hline RA & 180 & 6 & 180 & 8 \\
RP & 160 & 5 & 235 & 5 \\
UP & 90 & 3 & 90 & 4 \\
\hline
\end{tabular}

Fonte: elaborada pelos autores, com base em dados dos prontuários dos pacientes.

O custo total com materiais médico e administrativo e medicamentos (MMAM), para cada etapa do procedimento cirúrgico, no período estudado, é apresentado na tabela 7. O gasto com materiais e medicamentos no período pré-operatório independe do tamanho do cálculo do paciente. O custo total do período préoperatório, em cada ano, foi calculado multiplicando-se o custo unitário de cada categoria de cirurgia pela quantidade de cirurgias realizadas. Cálculo semelhante foi efetuado para o custo total, em cada ano, com material, na etapa da cirurgia.

\section{Tabela 7}

Custo com material médico, administrativo e medicamentos - pré-operatório

\begin{tabular}{|c|c|c|c|c|c|c|}
\hline \multirow[b]{2}{*}{ MМАM } & \multirow{2}{*}{$\begin{array}{c}\text { Pré- } \\
\text { operatório }\end{array}$} & \multicolumn{2}{|c|}{ Cirurgia } & \multicolumn{2}{|c|}{ PMP } & \multirow{2}{*}{$\begin{array}{c}\text { TOTAL } 2001 \\
2003 \\
\end{array}$} \\
\hline & & $<2 \mathrm{~cm}$ & $>2 \mathrm{~cm}$ & $<2 \mathrm{~cm}$ & $>2 \mathrm{~cm}$ & \\
\hline Custo total - 2001 & 341.35 & $1,809.06$ & $4,430.95$ & $1,475.55$ & $4,061.79$ & $12,118.70$ \\
\hline Custo total - 2002 & 552.98 & $3,748.92$ & $4,655.58$ & $3,130.69$ & $4,416.53$ & $16,504.69$ \\
\hline Custo total - 2003 & 927.86 & $5,344.74$ & $7,137.77$ & $5,556.23$ & $5,814.58$ & $24,781.18$ \\
\hline TOTAL 2001 a 2003 & $1,822.19$ & $10,902.72$ & $16,224.30$ & $10,162.47$ & $14,292.90$ & $53,404.58$ \\
\hline
\end{tabular}

Fonte: elaborada pelos autores.

A tabela 8 apresenta o cálculo da depreciação e da capacidade não utilizada para a cirurgia, no período 200103. O custo dos bens móveis e dos bens imóveis foi atualizado pelo índice INPC-IBGE, em 31-12-2003. A 
depreciação na etapa pré-operatória e no PMP foram calculados para bens móveis (por exemplo, cama, mesa, criado, mesa de refeições, suporte para soro) e imóveis (quarto com $25 \mathrm{~m}^{2}$ ) (tabela 8). A vida útil estimada para bens móveis é de 10 anos e para bens imóveis, 25 anos. A depreciação anual dos bens móveis e imóveis no período pré-operatório, no período estudado, foi obtida com o seguinte cálculo: custo unitário de R $\$ 2,94$ $(\mathrm{R} \$ 0,24+\mathrm{R} \$ 2,69$, ver tabela 8) multiplicado pela quantidade total de cirurgias de cada ano (tabela 5). Para o período de permanência do paciente, a depreciação anual dos bens móveis e imóveis resultou da multiplicação do custo unitário por dia de permanência $(\mathrm{R} \$ 2,94) x$ quantidade de cirurgias de cada categoria (tabela 5) $x$ o PMP do paciente em cada categoria de cirurgia (tabela 6).

O custo para se equipar uma sala no centro cirúrgico para tratamento do cálculo urinário é de $\mathrm{R} \$ 345.710,82$, com vida útil estimada em 15 anos, resultando numa depreciação anual de R\$23.047,39. Os equipamentos do centro cirúrgico não têm valor residual. $O$ custo de construção da sala de cirurgia é de $R \$ 40.000,00$ (sala de $40 \mathrm{~m}^{2}$ ) e a vida útil estimada é de 25 anos, resultando numa depreciação anual de $\mathrm{R} \$ 1.600,00$. Por sua vez, anualmente, a manutenção da sala de cirurgia sai por $\mathrm{R} \$ 11.433,45$. Assim, as bases de cálculo anuais para depreciação e capacidade não utilizada de bens móveis e imóveis são de $\mathrm{R} \$ 34.480,84$ e de $\mathrm{R} \$ 1.600,00$, respectivamente (tabela 8).

Para avaliar a depreciação e a capacidade não utilizada, foram calculadas as capacidades prática e normal da sala do centro cirúrgico, usada no tratamento do cálculo urinário (tabela 8). Teoricamente, o centro cirúrgico opera 24 horas por dia, durante todo o ano. Contudo, a capacidade prática é de 18 horas por dia, cinco dias por semana. Em 2001, o centro cirúrgico reservava uma sala, dois dias por semana, num total de 16 horas semanais, para cirurgias de cálculo urinário. A partir do ano seguinte, o número de salas aumentou para duas e a quantidade de horas semanais para 24. Dessa forma, antes de tudo, foi calculada a capacidade prática de uma sala do centro cirúrgico (18 $\times 52 \times 60 \times 5=280.800$ minutos) e, posteriormente calculada a capacidade prática dos horários disponibilizados para a urologia $(16 \times 52 \times 60=49.920$, em 2001, e $24 \times 52 \times 60=74.880$, em 2002 e 2003) (tabela 8). A capacidade normal foi calculada multiplicando-se a quantidade de cirurgias (tabela 5) pela duração de cada categoria de cirurgia (tabela 6). 


\section{Tabela 8}

\section{Depreciação de bens móveis e imóveis - período pré-operatório}

\begin{tabular}{|c|c|c|}
\hline DESCRIÇÃO & $\begin{array}{c}\text { Alternativas } \\
1,2 \text { e } 4\end{array}$ & $\begin{array}{c}\text { Alternativa } \\
3\end{array}$ \\
\hline \multicolumn{3}{|l|}{ Pré-operatório e prazo médio de permanência } \\
\hline a) Vida útil dos bens móveis - em anos & 10 & 10 \\
\hline b) Vida útil dos bens imóveis - em anos & 25 & 25 \\
\hline c) Custo dos bens móveis & $\mathrm{R} \$ 632.38$ & $\mathrm{R} \$ 632.38$ \\
\hline d) Custo dos bens imóveis & $\mathrm{R} \$ 17,500.00$ & $\mathrm{R} \$ 17,500.00$ \\
\hline e) Depreciação dos bens móveis por dia de permanência (c / a / número de semanas/5) & $\mathrm{R} \$ 0.24$ & $\mathrm{R} \$ 0.24$ \\
\hline f) Depreciação dos bens imóveis por dia de permanência (d / b / número de semanas / 5) & $\mathrm{R} \$ 2.69$ & $\mathrm{R} \$ 2.69$ \\
\hline \multicolumn{3}{|l|}{ Centro cirúrgico } \\
\hline a) Vida útil da sala no centro cirúrgico - em anos & 15 & 15 \\
\hline b) Vida útil dos bens imóveis - em anos & 25 & 25 \\
\hline c) Custo do equipamento da sala no centro círurgico & $\mathrm{R} \$ 345,710.82$ & $\mathrm{R} \$ 345,710.82$ \\
\hline d) Custo dos bens imóveis & $\mathrm{R} \$ 40,000.00$ & $\mathrm{R} \$ 40,000.00$ \\
\hline e) Manutenção - anual & $\mathrm{R} \$ 11,433.45$ & $\mathrm{R} \$ 11,433.45$ \\
\hline f) Base de cálculo anual dos bens móveis $((\mathrm{c} / \mathrm{a})+\mathrm{e})$ & $\mathrm{R} \$ 34,480.84$ & $\mathrm{R} \$ 34,480.84$ \\
\hline g) Base de cálculo anual dos bens imóveis (d / b) & $\mathrm{R} \$ 1,600.00$ & $\mathrm{R} \$ 1,600.00$ \\
\hline h) Capacidade prática do centro cirúrgico - em minutos $(18 \times 52 \times 60 \times 5)$ & 280,800 & 280,800 \\
\hline i) Capacidade prática da Urologia - 2001 - em minutos ( 16 × 52 x 60) & 49,920 & 49,920 \\
\hline j) Capacidade prática da Urologia - 2002 e 2003 - em minutos ( 24 x 52 x 60) & 74,880 & 74,880 \\
\hline $\begin{array}{l}\text { k) Capacidade normal - 2001- em minutos (duração de cada categoria de cirur } \\
\text { quantidade de cada categoria de cirurgia) }\end{array}$ & 3,080 & 0 \\
\hline 1) Capacidade normal - 2002- em minutos (idem k) & 4,645 & 21,917 \\
\hline m) Capacidade normal - 2003- em minutos (idem k) & 9,635 & 54,799 \\
\hline n) Capacidade não utilizada - 2001-em minutos (i - k) & 46,840 & 49,920 \\
\hline o) Capacidade não utilizada - 2002- em minutos $(1-1)$ & 70,235 & 52,963 \\
\hline p) Capacidade não utilizada - 2003- em minutos (j - m) & 65,245 & 20,081 \\
\hline q) Depreciação dos bens móveis - por minuto (f / h) & $\mathrm{R} \$ 0.12$ & $\mathrm{R} \$ 0.12$ \\
\hline r) Depreciação dos bens imóveis - por minuto $(\mathrm{g} / \mathrm{h})$ & $\mathrm{R} \$ 0.01$ & $\mathrm{R} \$ 0.01$ \\
\hline s) Depreciação dos bens móveis - capacidade prática - 2001 (q x i) & $6,129.93$ & $6,129.93$ \\
\hline t) Depreciação dos bens imóveis - capacidade prática - 2001 (r x i) & 284.44 & 284.44 \\
\hline u) Depreciação dos bens móveis - capacidade prática - 2002/2003 (q x j) & $\mathrm{R} \$ 9,194.89$ & $\mathrm{R} \$ 9,194.89$ \\
\hline v) Depreciação dos bens imóveis - capacidade prática - 2002/2003 (r x j) & $\mathrm{R} \$ 426.67$ & $\mathrm{R} \$ 426.67$ \\
\hline x) Depreciação dos bens móveis - capacidade normal - 2001 (q x k) & $\mathrm{R} \$ 378.21$ & $\mathrm{R} \$ 0.00$ \\
\hline z) Depreciação dos bens imóveis - capacidade normal - 2001 (r x k) & $\mathrm{R} \$ 17.55$ & $\mathrm{R} \$ 0.00$ \\
\hline aa) Depreciação dos bens móveis - capacidade normal - 2002 (q x l) & $\mathrm{R} \$ 570.38$ & $\mathrm{R} \$ 2,691.28$ \\
\hline ab) Depreciação dos bens imóveis - capacidade normal - 2002 ( r x l) & $\mathrm{R} \$ 26.47$ & $\mathrm{R} \$ 124.88$ \\
\hline ac) Depreciação dos bens móveis - capacidade normal - 2003 (q xm) & $\mathrm{R} \$ 1,183.13$ & $\mathrm{R} \$ 6,729.02$ \\
\hline ad) Depreciação dos bens imóveis - capacidade normal - 2003 ( $\mathrm{r} \mathrm{x} \mathrm{m}$ ) & $\mathrm{R} \$ 54.90$ & $\mathrm{R} \$ 312.24$ \\
\hline ae) Bens móveis - capacidade não utilizada - 2001 (n x q) & $\mathrm{R} \$ 5,751.72$ & \\
\hline af) Bens imóveis - capacidade não utilizada - 2001 (n x r) & $\mathrm{R} \$ 266.89$ & \\
\hline ag) Bens móveis - capacidade não utilizada - 2002 (o x q) & $\mathrm{R} \$ 8,624.51$ & $\mathrm{R} \$ 6,503.61$ \\
\hline ah) Bens imóveis - capacidade não utilizada - 2002 (o x r) & $\mathrm{R} \$ 400.20$ & $\mathrm{R} \$ 301.78$ \\
\hline ai) Bens móveis - capacidade não utilizada - 2003 (p x q) & $\mathrm{R} \$ 8,011.76$ & $\mathrm{R} \$ 2,465.87$ \\
\hline aj) Bens imóveis - capacidade não utilizada - 2003 (p x r) & $\mathrm{R} \$ 371.77$ & $\mathrm{R} \$ 114.42$ \\
\hline
\end{tabular}

Fonte: elaborada pelo autores. 
A depreciação dos bens móveis, obtida pela divisão da base de cálculo do centro cirúrgico $(\mathrm{R} \$ 34.480,84)$ pela capacidade prática do centro (280.800 minutos) foi de $\mathrm{R} \$ 0,1228$ por minuto. Multiplicando esse valor pela capacidade prática da urologia, em cada ano, chega-se à base de cálculo para a depreciação de bens móveis ( $\mathrm{R} \$ 6.129,93$, em 2001, e R $\$ 9.194,89$, em 2002 e 2003) (tabela 8). Assim, o custo com depreciação de bens móveis, por exemplo, em 2001, foi de $\mathrm{R} \$ 378,21$ ( $\mathrm{R} \$ 0,1228$ x 3.080). O mesmo raciocínio pode ser aplicado para avaliar a depreciação dos bens imóveis. Para calcular a despesa com a capacidade não utilizada, basta deduzir da base de cálculo da urologia o custo com depreciação. Por exemplo, para o ano de 2001, a despesa com a capacidade não utilizada dos bens móveis foi de $\mathrm{R} \$ 5.751,72$ ( $\mathrm{R} \$ 6.129,93$ - $\mathrm{R} \$ 378,21$ ).

A tabela 9 apresenta os resultados obtidos com a cirurgia para litíase urinária em 2001, 2002 e 2003, com base nos custos e receitas relevantes. Destacam-se os resultados 1 e 2, negativos para todo o período estudado.

\section{Tabela 9}

Resultado do procedimento de cirurgia - 2001-03 (R\$)

\begin{tabular}{|c|c|c|c|c|}
\hline DESCRIÇÃO & 2001 & 2002 & 2003 & Total \\
\hline Receita total & $15,322.74$ & $24,170.62$ & $42,659.42$ & $82,152.78$ \\
\hline \multicolumn{5}{|l|}{ Custos } \\
\hline Pré-operatório e setup & $2,092.70$ & $3,502.63$ & $6,181.92$ & $11,777.25$ \\
\hline Mão-de-obra & $1,695.58$ & $2,855.71$ & $5,086.73$ & $9,638.02$ \\
\hline M M AM & 341.35 & 552.98 & 927.86 & $1,822.19$ \\
\hline Depreciação - bens móveis & 4.62 & 7.78 & 13.86 & 26.27 \\
\hline Depreciação - bens imóveis & 51.15 & 86.15 & 153.46 & 290.77 \\
\hline Cirurgia & $11,537.99$ & $16,394.47$ & $29,055.90$ & $56,988.36$ \\
\hline Mão-de-obra & $4,902.22$ & $7,393.12$ & $15,335.36$ & $27,630.70$ \\
\hline M M AM & $6,240.01$ & $8,404.50$ & $12,482.51$ & $27,127.02$ \\
\hline Depreciação - bens móveis & 378.21 & 570.38 & $1,183.13$ & $2,131.72$ \\
\hline Depreciação - bens imóveis & 17.55 & 26.47 & 54.90 & 98.92 \\
\hline Permanência & $16,366.77$ & $22,439.12$ & $34,345.61$ & $73,151.50$ \\
\hline Mão-de-obra & $10,491.84$ & $14,392.87$ & $22,141.10$ & $47,025.81$ \\
\hline M M AM & $5,537.35$ & $7,547.21$ & $11,370.81$ & $24,455.37$ \\
\hline Depreciação - bens móveis & 27.97 & 41.35 & 69.08 & 138.39 \\
\hline Depreciação - bens imóveis & 309.62 & 457.69 & 764.62 & $1,531.92$ \\
\hline Alta & 190.48 & 320.81 & 571.44 & $1,082.73$ \\
\hline Mão-de-obra & 190.48 & 320.81 & 571.44 & $1,082.73$ \\
\hline Total Custo & $30,187.94$ & $42,657.02$ & $70,154.86$ & $142,999.83$ \\
\hline Resultado 1 & $(14,865.21)$ & $(18,486.40)$ & $(27,495.44)$ & $(60,847.05)$ \\
\hline Capacidade não-utilizada & $6,018.61$ & $9,024.71$ & $8,383.53$ & $23,426.85$ \\
\hline Resultado 2 & $(20,883.82)$ & $(27,511.11)$ & $(35,878.97)$ & $(84,273.89)$ \\
\hline
\end{tabular}

Fonte: elaborada pelos autores.

\section{Análise dos resultados}

A primeira decisão do Hospital Universitário de Brasília poderia ser a de manter o status quo. Nesse caso, o hospital não investiria no equipamento de litotripsia e realizaria em 2002 e 2003 a mesma quantidade de cirurgias realizadas em 2001, com o mesmo mix de cirurgias. Para calcular os resultados dessa alternativa, os custos e receitas de 2001 (tabela 9) foram multiplicados por dois. O resultado é negativo em $\mathrm{R} \$ 41.767,64$, incluída a despesa com a capacidade não utilizada (tabela 10).

A segunda alternativa seria o HUB aumentar a capacidade instalada para realizar um número maior de cirurgias para o tratamento da litíase urinária. Essa decisão foi tomada, aumentado-se o número de médicos, de horas e de salas de cirurgias disponíveis para os anos de 2002 e 2003. Para calcular os custos e as receitas dessa opção foram somados os custos e as receitas das cirurgias feitas nesses dois anos (tabela 9). O resultado também é negativo, em $\mathrm{R} \$ 63.390,08$, incluindo $\mathrm{R} \$ 17.408,23$ da despesa com capacidade não utilizada (tabela 10).

\section{Tabela 10}




\section{Análise diferencial}

\begin{tabular}{|c|c|c|c|c|c|c|c|}
\hline Descrição & $\begin{array}{c}\text { Alternativa } \\
1 \\
\end{array}$ & $\begin{array}{c}\text { Alternativa } \\
\mathbf{2} \\
\end{array}$ & $\begin{array}{c}\text { Alternativa } \\
\mathbf{3} \\
\end{array}$ & $\begin{array}{c}\text { Alternativa } \\
4 \\
\end{array}$ & $\begin{array}{c}\text { Diferencial } 1 \\
(2)-(1)\end{array}$ & $\begin{array}{c}\text { Diferencial } 2 \\
(3)-(1)\end{array}$ & $\begin{array}{c}\text { Diferencial } 3 \\
(4)-(1) \\
\end{array}$ \\
\hline Receita total & $30.645,48$ & $66.830,04$ & $388.364,14$ & $522.649,19$ & $36.184,57$ & $357.718,66$ & $492.003,71$ \\
\hline Custos & & & & & & & ( \\
\hline Mão-de-obra & $34.560,24$ & $68.097,14$ & $370.143,33$ & $96.029,43$ & $33.536,90$ & $335.583,09$ & $61.469,19$ \\
\hline MMAM & $24.237,41$ & $41.285,87$ & $217.530,42$ & $45.140,87$ & $17.048,46$ & $193.293,01$ & $20.903,46$ \\
\hline Depreciação & $1.578,24$ & $3.428,87$ & $18.581,26$ & $25.108,25$ & $1.850,63$ & $17.003,02$ & $23.530,01$ \\
\hline Total de custos & $60.375,89$ & $112.811,89$ & $606.255,01$ & $166.278,55$ & $52.436,00$ & $545.879,12$ & $105.902,67$ \\
\hline Resultado 1 & $(29.730,41)$ & $(45.981,84)$ & $(217.890,87)$ & $356.370,64$ & $(16.251,43)$ & $(188.160,46)$ & $386.101,05$ \\
\hline \multicolumn{8}{|l|}{ Despesas } \\
\hline $\begin{array}{l}\text { Capacidade não } \\
\text { utilizada } \\
\text { Provisão para } \\
\text { obsolescência }\end{array}$ & $12.037,23$ & $17.408,23$ & $9.385,69$ & $244.127,33$ & $5.371,01$ & $(2.651,54)$ & $232.090,11$ \\
\hline Total de despesas & $12.037,23$ & $17.408,23$ & $9.385,69$ & $363.337,70$ & $5.371,01$ & $(2.651,54)$ & $351.300,47$ \\
\hline Resultado 2 & $(41.767,64)$ & $(63.390,08)$ & $(227.276,56)$ & $(6.967,06)$ & $(21.622,44)$ & $(185.508,93)$ & $34.800,58$ \\
\hline
\end{tabular}

Fonte: elaborada pelos autores.

A terceira alternativa seria não investir no litotritor, mas atender a tantos pacientes quantos seriam atendidos caso o hospital tivesse adquirido o equipamento realizando apenas cirurgias. Assim, a quantidade de cirurgia será igual à quantidade de cirurgias da segunda opção + a quantidade de pacientes atendidos na litotripsia em 2002 e 2003. Para projetar essa opção será mantido o mesmo mix de cirurgias realizadas nesses dois anos. Antes de tudo, foi calculada a participação de cada categoria de cirurgia, por tamanho do cálculo, no total de cirurgias realizadas em 2002 e 2003 (tabela 11). Em seguida, multiplicado o percentual obtido na tabela 11 pela quantidade de pacientes atendidos no serviço de litotripsia e somada a quantidade de cirurgias efetivamente realizadas em cada ano (tabela 11). Seriam assim, realizadas 528 cirurgias.

\section{Tabela 11}

\section{Mix de cirurgia para projeção da terceira alternativa}

\begin{tabular}{|c|c|c|c|c|c|}
\hline \multirow[b]{2}{*}{ QUANTIDADE } & \multicolumn{2}{|c|}{2,002} & \multicolumn{2}{|c|}{2003} & \multirow[b]{2}{*}{ TOTAL } \\
\hline & $<2 \mathrm{~cm}$ & $>2 \mathrm{~cm}$ & $<2 \mathrm{~cm}$ & $>2 \mathrm{~cm}$ & \\
\hline a) RA & 6 & 8 & 5 & 6 & 25 \\
\hline b) $\mathrm{RP}$ & 1 & 3 & 15 & 17 & 38 \\
\hline c) UP & 10 & 4 & 12 & 2 & 33 \\
\hline d) Total cirurgia $(a+b+c)$ & 17 & 15 & 32 & 25 & 96 \\
\hline e) RA (a / d) & $35 \%$ & $53 \%$ & $16 \%$ & $24 \%$ & $26 \%$ \\
\hline f) $R P(b / d)$ & $6 \%$ & $20 \%$ & $47 \%$ & $68 \%$ & $40 \%$ \\
\hline g) UP (c / d) & $59 \%$ & $27 \%$ & $38 \%$ & $8 \%$ & $34 \%$ \\
\hline h) Quantidade de pacientes (Leco) & 112 & 19 & 267 & 41 & 439 \\
\hline i) $\mathrm{RA}((\mathrm{e} \times \mathrm{h})+\mathrm{a})$ & 46 & 18 & 47 & 16 & 126 \\
\hline j) RP $((f \times h)+b)$ & 8 & 7 & 140 & 45 & 199 \\
\hline k) UP $((g \times h)+c)$ & 76 & 9 & 112 & 5 & 202 \\
\hline l) Total cirurgia - alternativa $3(i+j+k)$ & 129 & 34 & 299 & 66 & 528 \\
\hline
\end{tabular}

Fonte: elaborada pelos autores. 
Observa-se que a terceira alternativa também apresentou resultado negativo em $\mathrm{R} \$ 227.276,56$, incluída a despesa com a capacidade não utilizada (tabela 10).

A quarta alternativa seria adquirir o litotritor. Nesse caso, foram consideradas quantas litotripsias e cirurgias foram efetivamente realizadas no HUB, no período estudado. Para o cálculo dessa escolha, foram somados os custos e receitas da tabela 6 (sem considerar os custos com telefone, água e energia) e os custos e receitas de 2002 e 2003 (tabela 9). Os custos com energia elétrica, água e ligações telefônicas não foram incluídos na análise diferencial devido a dificuldades de obtenção de informações, pois inexiste qualquer controle sobre o consumo desses recursos no centro cirúrgico. Essa opção também apresentou resultado negativo quando foi incluída a capacidade não utilizada e feita a provisão para obsolescência - R $\$ 6.967,06$. Entretanto, é a única possibilidade que apresenta resultado positivo antes da inclusão desses fatores - R\$356.370,64 (tabela 10).

A análise diferencial das possibilidades de escolha do HUB foi realizada em comparação com a primeira alternativa (tabela 10). Portanto, a quarta alternativa seria a melhor para o hospital, ou seja, investir no litotritor. Tal escolha, em relação à primeira alternativa, leva a um resultado diferencial positivo da ordem de $\mathrm{R} \$ 34.800,58$. Caso se opte pela alternativa 1 , o resultado seria negativo em $\mathrm{R} \$ 41.767,64$. Na hipótese de adotar a segunda alternativa, o prejuízo seria acrescido de $\mathrm{R} \$ 21.622,44$; um acréscimo que sobe para $\mathrm{R} \$ 185.508,93$, numa comparação com a terceira alternativa.

A análise diferencial também poderia ser feita entre as alternativas 4 e 3; ou seja, seria comparada a alternativa de se atender à mesma demanda, apenas com o recurso à cirurgia (alternativa 3) com a que recorre à cirurgia e à litotripsia (alternativa 4). Percebe-se que o resultado diferencial positivo apurado na comparação entre as alternativas 4 e 1 é de $\mathrm{R} \$ 34.800,58$ (tabela 10) e que sobe para $\mathrm{R} \$ 220.309,50$ ( $\mathrm{R} \$ 227.276,56$ - $\mathrm{R} \$ 6.967,06$ ), ratificando a escolha da alternativa 4 como a melhor para o HUB.

\section{Discussão dos resultados da pesquisa utilizando a técnica de simulação}

Para a discussão sobre os resultados da pesquisa será empregada a técnica de simulação. As simulações são utilizadas para predizer, explicar, exercitar e ajudar a identificar soluções "ótimas" (EVANS e OLSON, 1998). Os modelos de simulação descrevem apenas os relacionamentos e fornecem informações para avaliação, ou seja, não determinam uma solução "ótima". Também podem ser determinísticos ou probabilísticos. Nos modelos determinísticos, todos os dados são conhecidos ou podem ser supostos com certeza. Os probabilísticos consideram a variável incerteza, descrevendo alguns dados por distribuições de probabilidade. Por fim, podem ser discretos ou contínuos, dependendo dos tipos de variáveis do modelo. Evans e Olson (1998), porém, consideram que a maioria dos modelos de simulação utiliza variáveis discretas e distribuições probabilísticas.

Nesta pesquisa, foi utilizado o modelo de simulação operacional de Monte Carlo, por meio do sistema crystal ball. Esse sistema automatiza o processo de simulação, aplicando uma média de valores ou uma distribuição de probabilidades em cada variável de incerteza. Dessa forma, para cada variável de previsão são consideradas variáveis de suposição. Por exemplo, para prever a variável receita, são estabelecidas algumas suposições como custo, despesas, margem de lucro e inflação. Assim, foram realizadas simulações para diversos cenários de incerteza que serão apresentados nas próximas subseções.

\section{Primeiro cenário: resultados diferenciais desta pesquisa}

O primeiro cenário para simulação considera as três análises diferenciais apresentadas na tabela 16. Foram realizadas seis simulações nesse cenário, sendo duas para cada alternativa diferencial. Na primeira simulação, o resultado 2 foi adotado como variável de previsão e estabelecidas as seguintes variáveis de suposição: receita, mão-de-obra, MMAM (materiais médicos e administrativo e medicamentos), depreciação, capacidade não utilizada e provisão para obsolescência. Na segunda simulação, realizada para cada alternativa diferencial, a variável de previsão mudou para o resultado 1 e foram excluídas duas variáveis de suposição: capacidade não utilizada e da provisão para obsolescência. Foi considerado que as variáveis receita, mão-de-obra e MMAM se comportam conforme uma distribuição normal de probabilidade e que as variáveis depreciação, capacidade não 
utilizada e provisão para obsolescência possuem distribuição uniforme. O nível de confiança é de $95 \%$ e a quantidade total de iterações realizadas durante cada simulação (trials) é de 50.000.

O gráfico de sensibilidade tem o objetivo de avaliar a influência de cada suposição (receita total, mão-de-obra, MMAM, depreciação, capacidade não utilizada e provisão para obsolescência) na variável de previsão. Os resultados são apresentados na tabela 12 .

\section{Tabela 12}

Correlaçães entre as variáveis de suposição e previsão no primeiro cenário

\begin{tabular}{|c|c|c|c|c|c|c|}
\hline \multirow{3}{*}{$\begin{array}{l}\text { VARIÁVEIS DE } \\
\text { SUPOSIÇÃO }\end{array}$} & \multicolumn{6}{|c|}{ CORRELAÇÕES COM A VARIÁVEL DE PREVISÃO } \\
\hline & \multicolumn{2}{|c|}{ Diferencial 1} & \multicolumn{2}{|c|}{ Diferencial 2} & \multicolumn{2}{|c|}{ Diferencial 3} \\
\hline & Resultado 1 & Resultado 2 & Resultado 1 & Resultado 2 & Resultado 1 & Resultado 2 \\
\hline Receita total & 0,68 & 0,67 & 0,66 & 0,66 & 0,99 & 0,94 \\
\hline Mão-de-obra & $-0,63$ & $-0,62$ & $-0,62$ & $-0,62$ & $-0,11$ & $-0,26$ \\
\hline MMAM & $-0,31$ & $-0,30$ & $-0,36$ & $-0,34$ & $-0,04$ & $-0,04$ \\
\hline Depreciação & $-0,02$ & $-0,03$ & $-0,01$ & $-0,02$ & $-0,03$ & $-0,03$ \\
\hline $\begin{array}{l}\text { Capacidade não } \\
\text { utilizada }\end{array}$ & & $-0,05$ & & $-0,00$ & & $-0,26$ \\
\hline $\begin{array}{l}\text { Provisão para } \\
\text { obsolescência }\end{array}$ & & & & & & $-0,12$ \\
\hline
\end{tabular}

Fonte: elaborada pelos autores.

A receita total foi a variável mais relevante nas seis simulações realizadas. Destacam-se as correlações de 0,94 e 0,99 apresentadas na alternativa diferencial 3, resultados 2 e 1, respectivamente (tabela 12). Nas demais alternativas diferenciais, a receita total também foi a variável que apresentou maior correlação com a variável resultado 2 (variando entre 0,66 e 0,68) (tabela 12). Assim, a alta correlação entre as variáveis receita e resultado 2 , nas três alternativas diferenciais, revela a necessidade de análise da receita no processo decisório.

Nas alternativas diferenciais 1 e 2, a correlação entre as variáveis mão-de-obra e resultado 2 foi de $-0,62$, representando a segunda maior correlação do ranking de correlações (tabela 12). A terceira posição nesse ranking foi ocupada pela variável MMAM, sendo que a correlação entre as variáveis MMAM e resultado 2 foi de -0,30 e -0,34, nas alternativas diferenciais 1 e 2, respectivamente. No entanto, com a incorporação do litotritor, alternativa diferencial 3 - resultado 2, a variável mão-de-obra caiu para o quarto lugar (correlação de aproximadamente -0,12), cedendo lugar para a capacidade não utilizada ( $2^{-}$lugar - correlação de aproximadamente $-0,26)$ e, para a provisão para obsolescência ( $3^{-}$lugar - correlação de aproximadamente 0,12 ). Esses resultados indicam a relevância do gerenciamento da capacidade na incorporação do equipamento de litotripsia, em virtude da representatividade da capacidade não utilizada e da provisão para obsolescência. Dessa forma, essas variáveis devem ser consideradas nas decisões, levando em conta a influência que exercem no resultado.

Entre as análises estatísticas fornecidas pelo sistema de simulação, destacam-se os limites mínimo e máximo de resultado da variável de previsão. Esses resultados estão compilados na tabela 13. 
Tabela 13

Limites máximo e mínimo -primeiro cenário -em $R \$$

\begin{tabular}{lrrrrrr}
\hline & \multicolumn{2}{c}{ Diferencial 1 } & \multicolumn{2}{c}{ Diferencial 2 } & \multicolumn{2}{c}{ Diferencial 3 } \\
\cline { 2 - 7 } & \multicolumn{1}{c}{ Resultado 1 } & \multicolumn{1}{c}{ Resultado 2 } & \multicolumn{1}{c}{ Resultado 1 } & \multicolumn{1}{c}{ Resultado 2 } & Resultado 1 & \multicolumn{1}{c}{ Resultado 2 } \\
\cline { 2 - 7 } Tabela 10 & $(16.251,43)$ & $(21.622,44)$ & $(188.160,46)$ & $(185.508,93)$ & $386.101,05$ & $34.800,58$ \\
Limite mínimo & $(38.389,95)$ & $(44.526,43)$ & $(400.663,54)$ & $(421.407,33)$ & $184.275,44$ & $(182.875,88)$ \\
Limite máximo & $5.200,10$ & $(2.487,14)$ & $27.236,84$ & $15.791,49$ & $596.847,43$ & $240.098,11$ \\
\hline
\end{tabular}

Fonte: elaborada pelos autores.

$\mathrm{Na}$ alternativa diferencial 1 , os valores da variável resultado 2 podem variar de $\mathrm{R} \$ 44.526,43$, negativo, a $\mathrm{R} \$ 2.487,14$, também negativo (tabela 13). Portanto, considerando as suposições estabelecidas, o resultado 2 , negativo em $\mathrm{R} \$ 21.622,44$, da alternativa diferencial 1 (tabela 10), assumirá somente valores negativos nas 50.000 iterações realizadas no sistema de simulação (nível de confiança de 95\%).

O resultado 2 da análise diferencial 2 (tabela 10), negativo em $\mathrm{R} \$ 185.508,93$, pode assumir valores positivos ou negativos, após as 50.000 iterações, variando de $\mathrm{R} \$ 421.407,33$, negativo, a $\mathrm{R} \$ 15.791,49$, positivo (tabela 13). Contudo, com base no limite mínimo, a maioria dos resultados 2 assumiu valores negativos na simulação.

$\mathrm{Na}$ alternativa diferencial 3, o resultado 2, positivo em $\mathrm{R} \$ 34.800,58$ (tabela 10 ), pode variar de $\mathrm{R} \$ 182.875,88$, negativo, a $\mathrm{R} \$ 240.098,11$, positivo, durante as 50.000 iterações (tabela 13). No entanto, a alternativa diferencial 3 é a única que apresenta o resultado 1 assumindo valores positivos em todas as iterações, variando de $\mathrm{R} \$ 184.275,44$, positivo, a $\mathrm{R} \$ 596.847,43$, positivo. Observa-se que o resultado 1 é apurado, sem serem levadas em conta as despesas com a capacidade não utilizada e provisão para obsolescência.

Assim, é possível inferir que existe maior probabilidade de um resultado positivo quando a empresa não incorre em despesas com capacidade não utilizada e provisão para obsolescência. Tal fato chama a atenção para a necessidade de gerenciamento adequado da capacidade.

Segundo o Dr. Rômulo Marocclo Filho, ${ }^{5}$ a capacidade não utilizada do equipamento de litotripsia do Hospital Universitário de Brasília decorre, antes de tudo, da falta de demanda, naquele hospital, por esse procedimento. As cólicas renais, normalmente, são diagnosticadas em serviços de emergência (pronto-socorro) e o HUB não dispõe de atendimento de emergência na área de urologia. Por conseguinte, a maioria dos pacientes com esse diagnóstico é, inicialmente, atendida em outro hospital que tenha serviço de emergência, onde acaba dando continuidade ao tratamento. Assim, o que pode estar acontecendo é que outro hospital público do Distrito Federal, que disponha de emergência na área de urologia, não consiga atender a demanda por litotripsia, enquanto o HUB permanece com capacidade ociosa.

\section{Segundo cenário: custos com o ensino}

O objetivo do segundo cenário de simulação é analisar o impacto das atividades de ensino nos resultados diferenciais de cada alternativa de decisão. Para isso, é preciso analisar o HUB desenvolvendo apenas atividades assistenciais. Nesse sentido, as áreas de litotripsia e cirurgia não mais disporiam de médicos residentes (foi considerado que essas áreas não recebem alunos de graduação), e nesse contexto, as principais modificações seriam:

- redução das receitas. Sem o desenvolvimento de atividades de ensino, o hospital não receberia mais os recursos do Fideps (21\% sobre o faturamento total);

- o hospital não responderia mais pela remuneração dos médicos residentes;

\footnotetext{
${ }^{5}$ Entrevista não estruturada realizada em 15-4-2004.
} 
- as funções dos residentes seriam exercidas por médicos do quadro do hospital. Por exemplo, estes dedicariam cinco minutos do seu tempo para auxiliarem os residentes na litotripsia, após o período de aprendizagem (tabela 2). Com a saída dos médicos residentes, os profissionais do quadro da instituição passariam a responder por todos os procedimentos, dedicando 30 minutos a cada um destes;

- o tempo necessário para executar as atividades seria idêntico nos períodos AP e pós-AP;

- o prazo médio de permanência do paciente seria reduzido. O HUB conseguiria cumprir o prazo médio de permanência estipulado pelo SUS na tabela de reembolso. Esse prazo médio de permanência é de quatro dias para as categorias de cirurgia RA e RP, independentemente do tamanho do cálculo. Para as cirurgias com categoria UP, o prazo médio de permanência estabelecido pelo SUS é de cinco dias, independentemente do tamanho do cálculo (os prazos efetivamente realizados constam da tabela 9).

A tabela 14 apresenta os resultados das alternativas 1, 2, 3 e 4, bem como dos resultados diferenciais. Destacase que considerando o cenário estabelecido, os resultados diferenciais das alternativas 2,3 e 4, em relação à alternativa 1 , são negativos.

\section{Tabela 14}

\section{Resultados diferenciais - segundo cenário}

\begin{tabular}{|c|c|c|c|c|c|c|c|}
\hline Descrição & $\begin{array}{c}\text { Alternativa } \\
1\end{array}$ & $\begin{array}{c}\text { Alternativa } \\
2\end{array}$ & $\begin{array}{c}\text { Alternativa } \\
\mathbf{3}\end{array}$ & $\begin{array}{c}\text { Alternativa } \\
4\end{array}$ & $\begin{array}{c}\text { Diferencial } 1 \\
\text { (2) - (1) }\end{array}$ & $\begin{array}{l}\text { Diferencial } 2 \\
\text { (3) - (1) }\end{array}$ & $\begin{array}{l}\text { Diferencial } 3 \\
\text { (4) - (1) }\end{array}$ \\
\hline Receita total & $25.326,84$ & $55.231,44$ & $320.962,10$ & $431.941,48$ & $29.904,60$ & $295.635,26$ & $406.614,64$ \\
\hline \multicolumn{8}{|l|}{ Custos } \\
\hline Mão-de-obra & $25.259,09$ & $56.132,88$ & $322.379,91$ & $82.096,39$ & $30.873,78$ & $297.120,81$ & $56.837,30$ \\
\hline MMAM & $20.507,20$ & $37.814,69$ & $208.202,18$ & $41.669,69$ & $17.307,48$ & $187.694,98$ & $21.162,48$ \\
\hline Depreciação & $1.378,62$ & $3.205,77$ & $18.201,24$ & $24.885,15$ & $1.827,15$ & $16.822,62$ & $23.506,53$ \\
\hline Total de custos & $47.144,92$ & $97.153,34$ & $548.783,33$ & $148.651,23$ & $50.008,42$ & $501.638,41$ & $101.506,31$ \\
\hline Resultado 1 & $(21.818,08)$ & $(41.921,90)$ & $(227.821,23)$ & $283.290,25$ & $(20.103,82)$ & $(206.003,15)$ & $305.108,33$ \\
\hline \multicolumn{8}{|l|}{ Despesas } \\
\hline $\begin{array}{l}\text { Capacidade não } \\
\text { utilizada }\end{array}$ & $12.037,23$ & $17.408,23$ & $9.385,69$ & $244.127,33$ & $5.371,01$ & $(2.651,54)$ & $232.090,11$ \\
\hline $\begin{array}{l}\text { Provisão para } \\
\text { obsolescência }\end{array}$ & & & & $119.210,36$ & 0,00 & 0,00 & $119.210,36$ \\
\hline Total de despesas & $12.037,23$ & $17.408,23$ & $9.385,69$ & $363.337,70$ & $5.371,01$ & $(2.651,54)$ & $351.300,47$ \\
\hline Resultado 2 & $(33.855,30)$ & $(59.330,13)$ & $(237.206,92)$ & $(80.047,44)$ & $(25.474,82)$ & $(203.351,62)$ & $(46.192,14)$ \\
\hline
\end{tabular}

Fonte: elaborada pelos autores.

Comparando os resultados apresentados na tabela 14 com os da tabela 10, é possível verificar que as receitas diminuíram numa proporção maior que a redução dos custos e, conseqüentemente, o resultado das quatro opções piorou. Uma inferência que pode ser feita é a de que as atividades de ensino elevam os custos das áreas de litotripsia e cirurgia no HUB. No entanto, o incremento na receita é superior ao dos custos. Na alternativa diferencial 3, por exemplo, as receitas caíram 21\% ( $\mathrm{R} \$ 406.614,64$, na tabela 14, e $\mathrm{R} \$ 492.003,71$, na tabela 10), enquanto os custos e despesas totais caíram apenas 12,33\% (R $\$ 656.408,80$, na tabela 14 , e $\mathrm{R} \$ 737.401,52$, na tabela 10).

A tabela 15 compila os resultados das simulações feitas com base nos resultados 2 das alternativas diferenciais 1,2 e 3 . O resultado 2 foi adotado como variável de previsão, e foram estabelecidas as seguintes variáveis de suposição: receita, mão-de-obra, MMAM (materiais médicos e administrativo e medicamentos), depreciação, capacidade não utilizada e provisão para obsolescência. Foi considerado que as variáveis receita, mão-de-obra e MMAM se comportam conforme distribuição normal de probabilidade e que as variáveis depreciação, 
capacidade não utilizada e provisão para obsolescência possuem distribuição uniforme. O nível de confiança é de $95 \%$ e a quantidade total de iterações realizadas durante cada simulação é de 50.000 .

Tabela 15

Limites máximo e mínimo - segundo cenário - em R\$

\begin{tabular}{lccc}
\hline & Diferencial 1 & Diferencial 2 & \multicolumn{1}{c}{ Diferencial 3 } \\
\cline { 2 - 4 } & Resultado 2 & Resultado 2 & Resultado 2 \\
\cline { 2 - 4 } Limite mínimo & $(43.945,98)$ & $(396.433,55)$ & $(229.804,90)$ \\
\hline Limite máximo & $(5.439,14)$ & $11.008,56$ & $139.176,48$ \\
\hline
\end{tabular}

$\mathrm{Na}$ alternativa diferencial 1 , o resultado 2 permaneceu negativo durante todas as 50.000 iterações, variando de $\mathrm{R} \$ 43.945,98$ negativo a $\mathrm{R} \$ 5.439,14$ negativo (tabela 15 ). Na alternativa diferencial 2 , o resultado 2 variou de $\mathrm{R} \$ 396.433,55$ negativo a $\mathrm{R} \$ 11.008,56$ positivo, demonstrando maior probabilidade de assumir valores negativos. Na alternativa diferencial 3, o resultado 2 pode variar de um limite mínimo de $\mathrm{R} \$ 229.804,90$ negativo a um limite máximo de $\mathrm{R} \$ 139.176,48$ positivo. Observa-se que os resultados das simulações realizadas no segundo cenário corroboram os resultados estatísticos das simulações realizadas no primeiro cenário. Apenas os resultados 2 das alternativas diferenciais 2 e 3 têm probabilidade de assumir valores positivos, sendo que a probabilidade da alternativa diferencial 3 é maior.

\section{Terceiro cenário: ponto de equilíbrio}

O terceiro cenário considera o ponto de equilíbrio do serviço de litotripsia, para o período de maio de 2002 a dezembro de 2003, levando em conta os custos relevantes estabelecidos na tabela 6 . No cálculo do ponto de equilíbrio, são considerados os custos com telefone, água e energia (tabela 16). Para atingir o ponto de equilíbrio, o serviço de litotripsia teria de realizar 595 sessões durante o período estudado. Dessas sessões, 24 e 40 delas seriam realizadas no período AP, em 2002 e 2003, respectivamente. No período pós-AP seriam realizadas 160 e 371 sessões, em 2002 e 2003, respectivamente, sendo que dessas sessões, nove iriam requerer analgesia, em 2002, e 29, em 2003.

\section{Tabela 16}

\section{Ponto de equilíbrio - serviço de litotripsia, alternativa 4 e alternativa diferencial 3}

\begin{tabular}{lccccc}
\hline & Ponto de & Alternativa & Alternativa & Alternativa & Diferencial 3 \\
Descrição & equilíbrio & $\mathbf{1}$ & $\mathbf{2}$ & $\mathbf{4}$ & $\mathbf{( 4 )}-\mathbf{( 1 )}$ \\
\hline Receita total & $542.444,72$ & $30.645,48$ & $66.830,04$ & $609.274,76$ & $578.629,28$ \\
Mão-de-obra & $35.094,51$ & $34.560,24$ & $68.097,14$ & $103.191,65$ & $68.631,41$ \\
MMAM & $4.587,45$ & $24.237,41$ & $41.285,87$ & $45.873,32$ & $21.635,91$ \\
Telefone, água e energia & $136.171,70$ & - & - & - & - \\
Depreciação & $24.682,15$ & $1.578,24$ & $3.428,87$ & $29.124,67$ & $27.546,43$ \\
Resultado 1 & $341.908,91$ & $(29.730,41)$ & $(45.981,84)$ & $431.085,12$ & $460.815,53$ \\
Capacidade não utilizada & $222.687,44$ & $12.037,23$ & $17.408,23$ & $238.730,03$ & $226.692,80$ \\
Provisão para obsolescência & $119.210,36$ & - & - & $119.210,36$ & $119.210,36$ \\
Resultado 2 & 11,11 & $(41.767,64)$ & $(63.390,08)$ & $73.144,73$ & $114.912,36$ \\
\hline
\end{tabular}

Fonte: elaborada pelos autores.

Os custos e as receitas (exceto os custos com telefone, água e energia), apurados no ponto de equilíbrio do serviço de litotripsia, foram somados aos custos e às receitas da alternativa 2 para apuração do resultado 2 da alternativa 4. Observa-se que o resultado da alternativa 4, que antes era negativo em $\mathrm{R} \$ 6.967,06$ (tabela 10), subiu para $\mathrm{R} \$ 73.144,73$, positivo (tabela 16). Assim, o resultado 2 da análise diferencial 3 (alternativa 4 menos a alternativa 1) subiu para $\mathrm{R} \$ 114.912,36$. 


\section{Conclusões e recomendações}

O acelerado progresso tecnológico na área de saúde tem encarecido a assistência médica, o que exige, cada vez mais, do governo federal, da indústria, de fornecedores e de profissionais e instituições de saúde a inclusão de análises de custo no planejamento, controle e avaliação de políticas de investimento em novas tecnologias para tratamento médico.

Assim, este estudo analisou o impacto do progresso tecnológico nos custos do tratamento da litíase urinária. Para tanto, efetuou pesquisa exploratória, por meio de um estudo de caso nas áreas de litotripsia e no centro cirúrgico do Hospital Universitário de Brasília (HUB), da Universidade de Brasília (UnB). O progresso tecnológico, para fins deste estudo, foi identificado na incorporação do aparelho litotritor, em maio de 2002, ao patrimônio do hospital. Portanto, foram analisados os custos e benefícios diferenciais das alternativas de tratamento (cirurgia e litotripsia) em diferentes cenários, no período 2001-03.

Foram identificados custos e receitas, considerando-se quatro possibilidades de decisão por parte da administração do HUB: manter o status quo; aumentar a capacidade de realização de cirurgias; oferecer apenas o procedimento de cirurgia, mas atendendo a toda a demanda dos pacientes com diagnóstico de cálculo urinário; ou adquirir o litotritor. As análises diferenciais foram realizadas em relação à alternativa 1. Os resultados indicaram a alternativa 4 (adquirir o litotritor) como a decisão mais adequada. Entre os três resultados diferenciais, apenas o da análise diferencial 3 (alternativa 4 menos alternativa 1) foi positivo. Porém, as simulações indicaram que essa decisão tem $43 \%$ de probabilidade de apresentar resultados negativos. Isso decorre principalmente da peso que as despesas com capacidade não utilizada e provisão para obsolescência tem nos custos e despesas totais (76\%). Assim, infere-se o quanto é relevante o gerenciamento adequado da capacidade no processo de aquisição de novas tecnologias.

Outra conclusão desta pesquisa é a de que a avaliação dos custos hospitalares deve incluir a análise do impacto das opções de investimento. O governo federal doou o equipamento de litotripsia ao HUB por meio do Programa de Modernização e Consolidação da Infra-estrutura Acadêmica das Ifes e Hospitais Universitários. Esse programa exigiu do hospital apenas informações sobre os prováveis benefícios que o equipamento traria as pacientes e a previsão de demanda. Portanto, não exigiu informações de custo para analisar a viabilidade da doação. Por sua vez, o hospital não analisou o impacto dessa doação nos custos dos procedimentos. Considerar esse custo durante o processo decisório possibilitaria ao governo federal promover uma distribuição dos recursos mais eficaz, priorizando os hospitais que oferecessem melhor relação custo/benefício à sociedade. Para o HUB, essas informações são importantes para o gerenciamento, a análise do ponto de equilíbrio e até para negociar o reembolso do SUS.

Outra vertente das conclusões está relacionada ao planejamento da capacidade de atendimento. Utilizando a capacidade prática para custeio dos produtos e serviços do HUB, é possível separar de forma precisa os custos da capacidade utilizada na prestação dos serviços, os custos da capacidade ociosa e as despesas ou perdas com a capacidade não utilizada. Essas mensurações são importantes para que os serviços sejam onerados apenas pelo custo da capacidade utilizada, principalmente, durante a depreciação de equipamentos dispendiosos e de vida útil física longa, como é o caso do litotritor.

Portanto, de acordo com esta pesquisa, o avanço tecnológico causa impacto nos custos do tratamento de litíase urinária pelo(a):

- aumento da capacidade instalada ; pois durante o período estudado, o litotritor não teve grande parte de sua capacidade aproveitada, gerando significativa despesa por essa capacidade não utilizada;

- despesa gerada pela obsolescência, uma vez que o acelerado progresso tecnológico na área de saúde, a coloca como um fator relevante ao se analisar os custos das diferentes formas de tratamento da calculose urinária.

A instalação do litotritor provocou aumento diferencial expressivo na receita do hospital, podendo tornar o investimento na nova tecnologia atrativo pelo aumento do reembolso do SUS. Contudo, isso não pode ser o 
fator preponderante na análise da viabilidade da incorporação do novo equipamento. A análise e o gerenciamento da demanda, dos custos, da capacidade e da qualidade são essenciais para se chegar ao ponto de equilíbrio ou ter lucro.

A capacidade não utilizada do equipamento de litotripsia decorre, segundo o Dr. Rômulo Marocclo Filho, antes de tudo, da falta de demanda por esse procedimento. Normalmente, as cólicas renais são diagnosticadas em serviços de emergência (prontos-socorros) e o HUB não dispõe desse serviço na urologia. Assim, a maioria dos pacientes com esse diagnóstico é, inicialmente, atendida em outro hospital que tenha emergência, onde continua com o tratamento. Pode ocorrer, então, de outro hospital do Distrito Federal com atendimento de emergência na urologia não estar conseguindo dar conta da demanda por litotripsia, enquanto o HUB apresenta capacidade ociosa.

Conclui-se, ainda, que a metodologia apresentada neste estudo pode ser aplicada em todos os hospitais, públicos ou privados, contribuindo para o melhor gerenciamento dos custos hospitalares e dos investimentos em novas tecnologias. Para futuras pesquisas, recomenda-se a utilização de dados prospectivos de pacientes, ou seja, que se analise a relação custo/benefício, à medida que o paciente seja atendido. Assim, é possível acompanhar mais detalhadamente a resolubilidade do procedimento e, de forma mais acurada, calcular os custos do atendimento, tanto para o hospital quanto para o paciente. 


\section{Referências}

ALMEIDA, W. S.; SCHOR, N. Epidemiological and metabolic evaluation in renal stone patients living in an specific region of Brazil. Brazilian Journal of Urology, v.27, n.5, p.432-439, Sept./Oct. 2001.

ANTHONY, R. N.; GOVINDARAJAN, V. Sistemas de controle gerencial. São Paulo: Atlas, 2001.

BAKER, L. C. Managed care and technology adoption in health care: evidence from magnetic resonance imaging. Journal of Health Economics, v.20, p.395-421, 2001.

BALFOUR, F. et al. Sand, sun and surgery. Business Week, p.48-49, Feb. 16, 2004.

BANTA, H. D.; GELIJNS, A. Health care costs: technology and policy. In: SCHRAMM, C. J. (Ed.). Health care and its costs. New York: The American Assembly, 1987. p.252-274.

BARBOSA, A. P.; MALIK, A. M. 0 perfil de utilização de tecnologia médica em hospitais filantrópicos: análise da experiência de quatro hospitais em São Paulo. In: ENANPAD, 2003, São Paulo. Anais... São Paulo: Anpad, 2003. CD-ROM.

BARNUM, H.; KUTZIN, J. Public hospitals in developing countries: resource use, cost, financing. Washington: The World Bank. 1993.

BECKER, G. S. New drugs cut costs, and medicare can help. Business Week, p.32, Mar. 22, 2004.

BOWEN, H. R. The costs of higher education: how much do colleges and universities spend per student and how much should they spend? San Francisco: Jossey-Bass Publishers, 1980.

BRANDON, B. G. et al. Incremental cost-effectiveness of initial cataract surgery. Ophthalmology, v.109, n.3, p.606-613, 2002.

BRASIL. Ministério da Saúde. Portaria conjunta n- 47, de 13 de agosto de 2001. Diário Oficial da República Federativa do Brasil, Brasília, DF, 16 ago. 2001. Seção I, Parte I, Suplemento 57-E, p.59.

BRASIL. Ministério da Saúde. Disponível em:

<http://dtr2001.saude.gov.br/bvs/terminologia.asp\#>. Acesso em: 20 fev. 2004.

BROWN, G. C. et al. Incremental cost effectiveness of laser photocoagulation for subfoveal choroidal neovascularization. Ophthalmology, v.107, n.7, p.1374-1380, July 2000.

CAREY, J. Drug REDD: must Americans always pay? Business Week, p.38-40, Oct. 13, 2003.

CHAMBÔ, J. L. Guia prático de urologia. Sociedade Brasileira de Urologia, 2004, Seção VIII, Capítulo 169 - Epidemiologia, etiologia, diagnóstico e tratamento clínico da litíase urinária. Disponível em: <http://sbu.org.br/publicacoes_guiapraticodeurologia.asp >. Acesso em: 28 abr. 2004.

CHING, H. Y. Manual de custos de instituições de saúde: sistemas tradicionais de custos e sistemas de custeio baseado em atividades (ABC). São Paulo: Atlas, 2001.

COOK, J.; RICHARDSON, J.; STREET, A. Cost utility analysis of treatment options for gallstone disease: final report. Centre for Health Program Evaluation. Working paper n.35, Apr. 1994. Disponivel em: <http://chpe.buseco.monash.edu.au/pubs/wp35.pdf>. Acesso em: 8 jan. 2004.

CUTLER, D. M.; McCLELLAN, M. Is technological change in medicine worth it? Health Affairs, Sept../Oct. 2001.

$\therefore \quad ;$ NEWHOUSE, J. P. The costs and benefits of intensive treatment. National Bureau of Economic Research. Working paper n.6514, 1998. Disponivel em: <http://www.nber.org/papers/w6514>. Acesso em: 24 out. 2003.

DILLON, R. D; NASH, J. F. The true relevance of relevant costs. The Accounting Review, v.LIII, n.1, Jan. 1978.

DOZET, A.; LYTTKENS, C. H.; NYSTEDT, P. Health care for the elderly: two cases of technology diffusion. Social Science \& Medicine, v.54, p.49-64, 2002

EVAN, A. et al. Shockwave Lithotripsy Program Project. Disponivel em: <http://anatomy.iupui.edu/lithotripsy/Whatis.html>. Acesso em: 19 abr. 2004.

EVANS, J. R.; OLSON, D. L. Introduction to simulation and risk analysis. New Jersey: Prentice Hall, 1998.

FALK, J. A. Gestão de custos para hospitais: conceitos, metodologias e aplicações. São Paulo: Atlas, 2001.

FOOTE, S. B. Tecnology and health reform. Progress in Pediatric Cardiology, v.4, p.65-70, 1995.

FUCHS, V. R. Economics, values, and health care reform. The American Economic Review, v.86, n.1, p.1-24, Mar. 1996.

GARCIA, J. E. R. Litiasis renal. Viatusalud, 14 Oct. 2002. Disponivel em: <http://www.viatusalud.com/Documento.asp?id=33>. Acesso em: 06 de junho de 2004.

GARRISON, R. H.; NOREEN, E. W. Contabilidade gerencial. 9. ed. Rio de Janeiro: LTC, 2001. 
HOF, R. D. Why tech will bloom again. Business Week, p.64-123, Aug. 18-25, 2003.

IBGE. Censo demográfico 2000. População residente, por situação do domicílio e sexo, segundo as grandes regiões e as unidades da federação. Brasil - grandes regiões. Disponivel em: <http://www.ibge.gov.br/censo/default.php>. Acesso em: 28 abr. 2004.

INGRAM, R.; ALBRIGHT, T.; HILL, J. Managerial accounting: information for decisions. Cincinnati: South-Western, 1997.

INNES, J.; MITCHELL, F. Overhead cost. London: Academic Press, 1993.

JOHNSON, D. B. et al. University of Wisconsin experience using the Doli S Lithotriptor. Urology, v.62, p.410-415, 2003.

KLIGERMAN, J. Assistência oncológica e incorporação tecnológica. Revista Brasileira de Cancerologia, v.47, p. 239-243, 2001.

LOTAN, Y. et al. Management of ureteral calculi: a cost comparison and decision making analysis. The Journal of Urology, v.167, p.16211629, Apr. 2002.

MARINHO, A. et al. Os determinantes dos investimentos em capital fixo no sistema hospitalar brasileiro: um guia metodológico integrado com bases de dados e fontes de informações. Ipea. Texto para discussão n.972, Rio de Janeiro, 2003. Disponivel em: <http://www.ipea.gob.br/pub/td/2003/td_0972.pdf>. Acesso em: 12 abr. 2004.

MCCLELLAN, M.; NOGUCHI, H. Technological change in heart-disease treatment: Does high tech mean low value? The American Economic Review, v.88, n.2, p.90-96, May 1998.

MENDES, E. V. Evolução histórica da prática médica: suas implicações no ensino, na pesquisa e na tecnologia médicas. Belo Horizonte: Pontif Univ Cat, 1984.

SCHOR, N.; HEILBERG, I. P. Cálculo renal é doença multifatorial. Disponivel em:

<http://www.samaritano.com.br/?id_noticia=10\&tid_not_conteudo=142>. Acesso em: 28 abr. 2004.

STREET, A. Gallstone disease: the cost of treatment. Centre for Health Program Evaluation. Working Paper n.29, Sept. 1993. Disponivel em: <http://chpe.buseco.monash.edu.au/pubs/wp29.pdf>. Acesso em: 8 jan. 2004.

STRUET, M. A. M. et al. Análise da aplicação do custeio baseado em atividades em hospitais públicos. In: CLADEIA, 2002, Porto Alegre, Anais... Porto Alegre: Cladeia, 2002. CD-ROM.

TULLOCK, G. The cost of medical progress. The American Economic Review, v.85, n.2, p.77-80, May 1995.

VARKARAKIS, J. et al. Comparison of success rates and financial cost of extracorporeal shock-wave lithotripsy in situ and after manipulation for proximal ureteral stones. Urological Research, v.31, n.4, p.286-290, 2003.

VASSALO, C. Por que os preços cobrados pelos hospitais brasileiros são tão altos? Exame, n.19, p.84-96, maio 1997.

VATTER, W. J. Accounting measurements of incremental cost. The Journal of Business of the University of Chicago, v.18, n.3, p.145-156, July 1945. 